\title{
Melhor preditor empírico aplicado aos modelos beta mistos
}

\author{
Ana Paula Zerbeto \\ DisSERTAÇÃO APRESENTADA \\ AO \\ Instituto De Matemática e Estatística \\ DA \\ Universidade DE SÃo Paulo \\ PARA \\ OBTENÇÃO DO TÍTULO \\ $\mathrm{DE}$ \\ Mestre em CiÊNCIAS \\ Programa: Estatística \\ Orientadora: Prof ${ }^{\mathrm{a}}$. Dr ${ }^{\mathrm{a}}$. Viviana Giampaoli
}

Durante o desenvolvimento deste trabalho o autor recebeu auxílio financeiro do CNPq/CAPES

São Paulo, 21 de fevereiro de 2014 


\section{Melhor preditor empírico aplicado aos modelos beta mistos}

Esta versão da dissertação contém as correções e alterações sugeridas pela Comissão Julgadora durante a defesa da versão original do trabalho, realizada em 21/02/2014. Uma cópia da versão original está disponível no

Instituto de Matemática e Estatística da Universidade de São Paulo.

Comissão Julgadora:

- Prof ${ }^{\mathrm{a}}$. Dr ${ }^{\mathrm{a}}$. Viviana Giampaoli (orientadora) - IME-USP

- Prof ${ }^{\mathrm{a}}$. Dra ${ }^{\mathrm{a}}$. Marcia D’Elia Branco - IME-USP

- Prof. Dr. Francisco José de Azevêdo Cysneiros - UFPE 


\section{Resumo}

ZERBETO, A. P. Melhor preditor empírico aplicado aos modelos beta mistos. 2014. Dissertação (Mestrado) - Instituto de Matemática e Estatística, Universidade de São Paulo, São Paulo, 2014.

Os modelos beta mistos são amplamente utilizados na análise de dados que apresentam uma estrutura hierárquica e que assumem valores em um intervalo restrito conhecido. Com o objetivo de propor um método de predição dos componentes aleatórios destes, os resultados previamente obtidos na literatura para o preditor de Bayes empírico foram estendidos aos modelos de regressão beta com intercepto aleatório normalmente distribuído. O denominado melhor preditor empírico (MPE) proposto tem aplicação em duas situações diferentes: quando se deseja fazer predição sobre os efeitos individuais de novos elementos de grupos que já fizeram parte da base de ajuste e quando os grupos não pertenceram à tal base. Estudos de simulação foram delineados e seus resultados indicaram que o desempenho do MPE foi eficiente e satisfatório em diversos cenários. Ao utilizar-se da proposta na análise de dois bancos de dados da área da saúde, observou-se os mesmos resultados obtidos nas simulações nos dois casos abordados. Tanto nas simulações, quanto nas análises de dados reais, foram observados bons desempenhos. Assim, a metodologia proposta se mostrou promissora para o uso em modelos beta mistos, nos quais se deseja fazer predições.

Palavras-chave: modelo beta misto, preditor de Bayes empírico, predição, efeitos aleatórios. 


\section{Abstract}

ZERBETO, A. P. Empirical best predictor for mixed beta regression models. 2014. Dissertação (Mestrado) - Instituto de Matemática e Estatística, Universidade de São Paulo, São Paulo, 2014.

The mixed beta regression models are extensively used to analyse data with hierarquical structure and that take values in a restricted and known interval. In order to propose a prediction method for their random components, the results previously obtained in the literature for the empirical Bayes predictor were extended to beta regression models with random intercept normally distributed. The proposed predictor, called empirical best predictor (EBP), can be applied in two situations: when the interest is predict individuals effects for new elements of groups that were already analysed by the fitted model and, also, for elements of new groups. Simulation studies were designed and their results indicated that the performance of EBP was efficient and satisfatory in most of scenarios. Using the propose to analyse two health databases, the same results of simulations were observed in both two cases of application, and good performances were observed. So, the proposed method is promissing for the use in predictions for mixed beta regression models.

Keywords: mixed beta regression model, empirical Bayes predictor, prediction, random effects. 


\section{Sumário}

Lista de Abreviaturas vii

$\begin{array}{ll}\text { Lista de Figuras } & \text { ix }\end{array}$

Lista de Tabelas

1 Introdução $\quad 1$

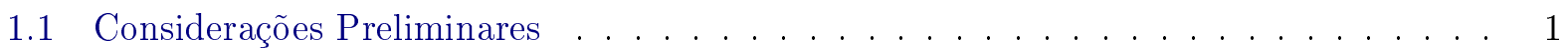

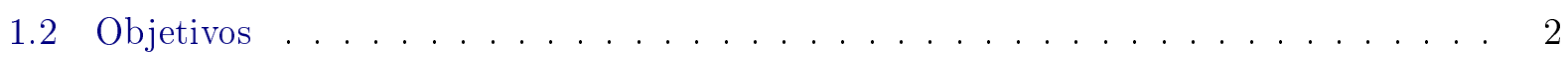

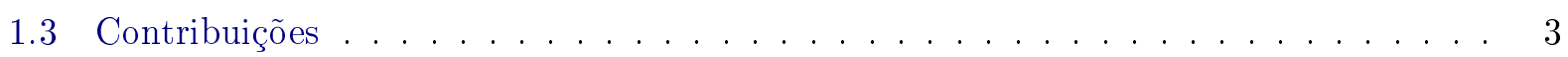

1.4 Organização do Trabalho . . . . . . . . . . . . . . . . . . . 3

2 Conceitos 5

2.1 Distribuição Beta . . . . . . . . . . . . . . . . . . . . 5

2.2 Modelo de Regressão Beta . . . . . . . . . . . . . . . . . . . . 7

2.3 Dados Correlacionados . . . . . . . . . . . . . . . . . . . . 7

2.4 Modelo de Regressão Beta com Efeitos Aleatórios . . . . . . . . . . . . . . . . . . 8

2.5 Melhor Preditor Empírico . . . . . . . . . . . . . . . . . . . . . . . 10

2.6 Medidas de Avaliação de Desempenho . . . . . . . . . . . . . . . . . 11

2.6.1 Raíz do erro quadrático médio de predição . . . . . . . . . . . . . . . . . . . . . . . . . . . . . . . . . . . 12

2.6 .2 Viés relativo médio . . . . . . . . . . . . . . . . . . . . 12

2.6.3 Resíduo quantílico aleatorizado . . . . . . . . . . . . . . . . 13

3 Predição nos Modelos de Regressão Beta com Intercepto Aleatório 15

3.1 Caso geral . . . . . . . . . . . . . . . . . . . . . . . 15

3.1 .1 Notações e definições . . . . . . . . . . . . . . . . . . . 15

3.1 .2 MPE para o caso geral . . . . . . . . . . . . . . . 16

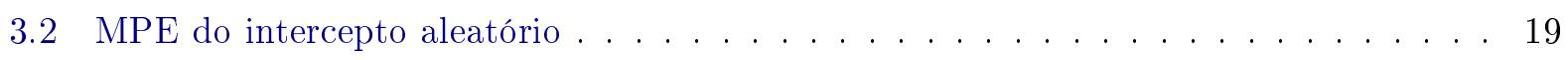

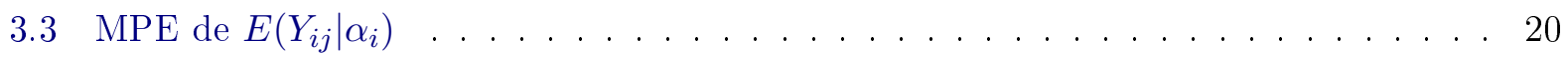

4 Estudo de Simulação $\quad 23$

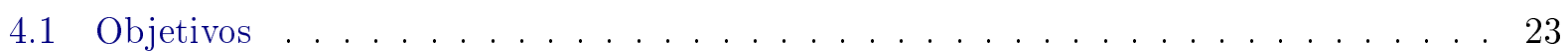

4.1.1 Objetivos das simulações do MPE para o intercepto aleatório . . . . . . . . . 24

4.1 .2 Objetivos das simulações do MPE para $\mu_{i j} \ldots \ldots \ldots \ldots \ldots$

4.2 Descrição do Estudo . . . . . . . . . . . . . . . . . . . . . . . 25

4.2 .1 Algoritmo de implementação . . . . . . . . . . . . . . . . 26 
4.3 Análise dos resultados . . . . . . . . . . . . . . . . . . 27

4.3.1 Resultados das simulações do MPE do intercepto aleatório . . . . . . . . . . 28

4.3.2 Resultados das simulações do MPE de $\mu_{i j} \ldots \ldots$. . . . . . . . . . . . . 33

5 Aplicações $\quad 37$

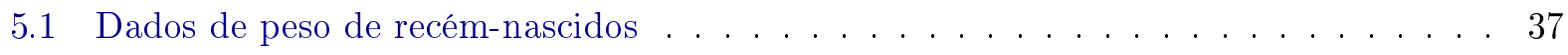

$5.1 .1 \quad$ Análises . . . . . . . . . . . . . . . . . . . . 38

5.2 Dados de pacientes diagnosticados com periodontite . . . . . . . . . . . 44

5.2 .1 Análises . . . . . . . . . . . . . . . . . . . . . 46

6 Conclusão $\quad \mathbf{5 5}$

6.1 Considerações Finais . . . . . . . . . . . . . . . . . . . . . . 55

6.2 Sugestões para Pesquisas Futuras . . . . . . . . . . . . . . . 56

Referências Bibliográficas $\quad 59$ 


\title{
Lista de Abreviaturas
}

\author{
BA Base de ajuste \\ BP Base de predição \\ EQM Erro Quadrático Médio \\ EQMP Erro Quadrático Médio de Predição \\ MP Melhor Preditor \\ MPE Melhor Preditor Empírico \\ REQM Raíz do Erro Quadrático Médio \\ REQMP Raíz do Erro Quadrático Médio de Predição \\ vrm Viés relativo médio
}




\section{Lista de Figuras}

2.1 Comparação entre as densidades da distribuição beta para diferentes valores dos parâmetros $(\mu, \phi) \ldots \ldots \ldots \ldots \ldots \ldots \ldots \ldots \ldots \ldots \ldots \ldots \ldots \ldots \ldots \ldots$

2.2 Comparação entre os modelos de regressão beta com efeitos fixos e com intercepto

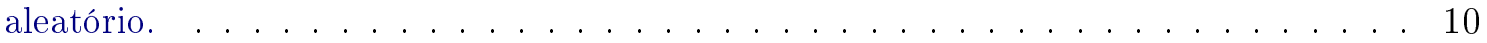

4.1 $p$-valor do teste de Shapiro-Wilk para os valores preditos do intercepto aleatório na base de ajuste. . . . . . . . . . . . . . . . . . . . . 28

$4.2 p$-valor do teste de Shapiro-Wilk para os valores preditos do intercepto aleatório na base de predição. . . . . . . . . . . . . . . . . . . . . . . . . . . 29

$4.3 p$-valor do teste de médias para os valores preditos do intercepto aleatório na base

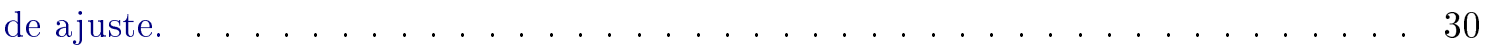

$4.4 p$-valor do teste de médias para os valores preditos do intercepto aleatório na base de predição. . . . . . . . . . . . . . . . . . . . . . . . 31

$4.5 p$-valor do teste de Bartlett para os valores preditos do intercepto aleatório . . . . . . 32

4.6 Boxplot dos erros puros de predição para as bases de ajuste e de predição. . . . . . . 34

4.7 QQ-plot dos resíduos quantílicos aleatorizados para as bases de ajuste e de predição. 35

5.1 Histograma do peso ao nascer dos recém-nascidos da base de ajuste. . . . . . . . . 40

5.2 Boxplot da variável peso ao nascer dos recém-nascidos da BA segundo a variável

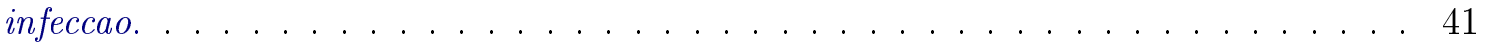

5.3 Estrutura hierárquica dos dados de gestantes. . . . . . . . . . . . . . . . . . . 41

5.4 Gráficos para diagnóstico do ajuste do modelo para a variável peso ao nascer dos dados de recém-nascidos. . . . . . . . . . . . . . . . . . . . . . 42

5.5 Valores observados e MPE da variável peso ao nascer segundo a variável infecção nos dados de recém-nascidos. . . . . . . . . . . . . . . . . . . . . . . 44

5.6 Estrutura hierárquica dos dados de periodontite. . . . . . . . . . . . . 46

5.7 Gráfico de perfis da variável anti-oxLDL para as bases de ajuste e de predição nos dados de periodontite. . . . . . . . . . . . . . . . . . 47

5.8 Histograma da variável anti-oxLDL da base de ajuste. . . . . . . . . . . . . . 48

5.9 Gráficos para diagnóstico do ajuste do modelo para a variável anti-oxLDL dos dados de periodontite. . . . . . . . . . . . . . . . . . . 49

5.10 Valores observados e MPE da variável anti-oxLDL para os pacientes da BA nos dados de periodontite. . . . . . . . . . . . . . . . . . 5 51

5.11 Valores observados e MPE da variável anti-oxLDL para os pacientes da BP nos dados de periodontite. 
5.12 Perfis médios dos valores observados e MPE da variável anti-oxLDL dos pacientes nos dados de periodontite. . . . . . . . . . . . . . . . . . 53 


\section{Lista de Tabelas}

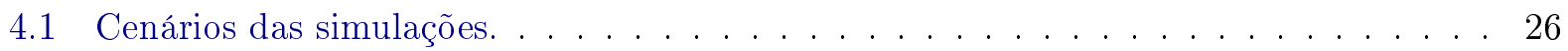

4.2 Medidas de desempenho da estimação de $\beta_{0}$ pelo modelo beta misto $\left(\beta_{0}=0,5\right) \ldots$. 27

4.3 Medidas de desempenho da estimação de $\beta_{1}$ pelo modelo beta misto $\left(\beta_{1}=1\right)$. . . . 27

4.4 Medidas de desempenho da estimação de $\phi$ pelo modelo beta $\operatorname{misto}(\phi=3) . \quad \ldots$. . 27

4.5 Taxa de rejeição do teste de Shapiro-Wilk para os valores preditos do intercepto

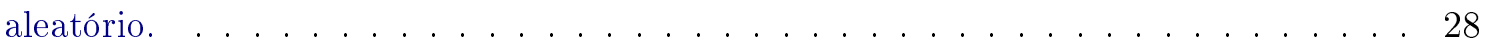

4.6 Taxa de rejeição do teste de médias para os valores preditos do intercepto aleatório. . 30

4.7 Estatísticas descritivas dos valores preditos do intercepto aleatório para a BA do

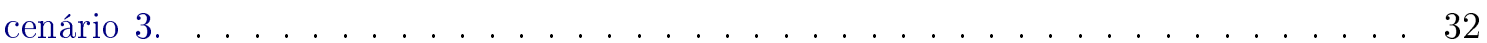

4.8 Taxa de rejeição do teste de Bartlett entre os valores preditos do intercepto aleatório das bases de ajuste e de predição. . . . . . . . . . . . . . . . . . . . 32

4.9 REQMP do MPE de $\mu_{i j}$ para os dados da BA e da BP. . . . . . . . . . . . 33

4.10 Viés relativo médio do MPE de $\mu_{i j}$ para os dados da BA e da BP. . . . . . . . . . 35

5.1 Estimativas dos parâmetros, erros padrões, valores t e $p$-valores do modelo ajustado para a variável peso ao nascer dos dados de recém-nascidos. . . . . . . . . . . . 43

5.2 Valores preditos dos interceptos aleatórios do modelo ajustado para a variável peso ao nascer para cada grupo dos dados de recém-nascidos. . . . . . . . . . . . . 43

5.3 Estimativas dos parâmetros, erros padrões, valores t e $p$-valores do modelo ajustado para a variável anti-oxLDL dos dados de periodontite. . . . . . . . . . . 50 


\section{Capítulo 1}

\section{Introdução}

\subsection{Considerações Preliminares}

No cenário de pesquisa, ao nível mundial, os estudos de dados com estrutura hierárquica em áreas como educação, saúde, marketing, ciências sociais, dentre outras, têm sido cada vez mais frequentes.

O desenvolvimento de tecnologias de armazenamento e processamento de dados mais eficientes aumenta cada vez mais a quantidade de estudos com dados agrupados, por exemplo, que aferem uma mesma medida em tempos diferentes; esta expansão, juntamente com o crescimento da facilidade de obtenção de informações através de meios de comunicação como a internet, incidem na maior necessidade de aplicação de modelos que considerem este tipo de estrututa em seu ajuste.

Pode-se citar como exemplos deste tipo de dados hierárquicos: medições diárias de temperatura de bairros de uma cidade ao longo de um mês, em que as medições de um mesmo bairro não são independentes, assim como em estudos de características físicas (pressão arterial, colesterol, peso) de pacientes ao longo do tempo. Outro exemplo muito citado em que os dados estão hierarquicamente agrupados é o caso de alunos em salas de aula, já que quando se remete a estudos de desempenho escolar desses alunos em exames, não é adequado pressupor que alunos de uma mesma sala de aula possuam desempenhos independentes, pois todos aprenderam parte do conteúdo avaliado com um mesmo docente.

Os modelos de regressão de efeitos fixos assumem, no geral, que as observações são independentes entre si. Levando-se em consideração que nos bancos de dados com estrutura hierárquica, as informações obtidas provêem de mesmo ambiente ou possuem características semelhantes, logo raramente são dados não correlacionados, então não é recomendável a aplicação desta classe de ajustes a eles. Assim, o ajuste de modelos multiníveis neste tipo de situação apresenta maior adequabilidade e robustez nos resultados.

Modelos de regressão com efeitos aleatórios são ferramentas estatísticas extremamente adequadas pra análise de dados multiníveis, também denominados hierárquicos; então, é de grande interesse o estudo dos diferentes aspectos desta classe de modelos, podendo ser citados como aspectos: desenvolvimento de estimadores eficientes, métodos de diagnóstico e métodos de predição.

Inicialmente estes modelos foram desenvolvidos para análise de variáveis respostas normalmente distribuídas por Laird e Ware (1982), atualmente uma grande diversidade de outras distribuições da variável resposta e dos efeitos aleatórios já foram abordadas. Neste trabalho, mais especifica- 
mente, tem-se interesse nos modelos de regressão beta mistos; cuja finalidade é ajustar variáveis contínuas restritas a um intervalo conhecido (a,b), tais como taxas, proporções, frações.

Esta classe de modelos, explorada em Figueroa-Zúñiga et al. (2013), Verkuilen e Smithson (2012) e Usuga (2013), tem a vantagem de possibilitar o ajuste de dados com distribuições assimétricas sem a utilização de transformações, o que proporciona maior facilidade de interpretação dos resultados.

Quando o interesse nestes modelos se remete ao campo da predição de efeitos aleatórios, é usual a utilização do método de Bayes empírico e de suas variações. Uma destas variações é o melhor preditor de Bayes empírico, que segundo Fitzmaurice et al. (2008), McCulloch et al. (2008) e Verbeke e Molenberghs (2009) é o método mais utilizado; isto ocorre em virtude da sua eficiência e confiabilidade para as análises destas predições.

Ainda falando do aspecto preditivo dos modelos mistos, podem ser consideradas duas situações de aplicação. Considere o exemplo das medições diárias de temperatura de bairros de diferentes subprefeituras de uma cidade ao longo de um mês: veja que pode-se desejar fazer a análise preditiva da temperatura de um bairro cujos dados de sua subprefeitura fizeram parte da base de ajuste do modelo ou de um bairro que não tem registros de medições de temperatura porque a subprefeitura a qual ele pertence não fez parte da análise. O primeiro caso refere-se à predição de um novo elemento de um grupo já estudado e o segundo caso refere-se à predição de elementos de um novo grupo.

Ambos os casos serão abordados ao longo deste trabalho, de forma a disponibilizar um método preditivo tão eficiente para novos grupos quanto o é para grupos já estudados.

Dessa forma, este trabalho se dedica, de forma geral, a propor e estudar o método de predição do melhor preditor de Bayes empírico em modelos beta mistos. Os objetivos deste trabalho estão apresentados de forma pontual na seção que segue.

\subsection{Objetivos}

O modelo de regressão beta com intercepto aleatório normal é um caso específico dos modelos aditivos generalizados para posição, escala e forma (Generalised Additive Models for Location Scale and Shape, GAMLSS) propostos por Rigby e Stasinopoulos (2005). Esta classe de modelos é usualmente utilizada por motivos como:

- levar em consideração a heterogeneidade entre os grupos de um determinado nível dos dados hierárquicos através da inclusão de interceptos aleatórios;

- por ser possível abranger o ajuste de grande diversidade de tipos de dados em virtude da flexibilidade da distribuição beta.

Devido a sua grande aplicabilidade, motivou-se neste trabalho o estudo desta classe de modelos em específico. Tem-se interesse em estudar diversos aspectos destes modelos, como estimação dos parâmetros, diagnóstico de adequabilidade do ajuste, predição e assim por diante; então, decidiu-se nesta dissertação por pesquisar um método de predição de acordo com o conteúdo esclarecido adi- 
ante.

O objetivo principal do trabalho de dissertação foi propor um novo método de predição de componentes, como efeitos aleatórios e funções deles, de modelos de regressão beta com intercepto aleatório normal; a este método deu-se o nome de melhor preditor empírico (MPE).

Os esforços se concentraram em adaptar resultados anteriormente obtidos para esta metodologia, em Morris (1983), Casella (1985), Carlin e Louis (2000) e Tamura (2012), aos modelos beta com intercepto aleatório normal expostos em Usuga (2013). Considerando sempre o caso de se predizer termos de novos grupos de forma a manter o mesmo desempenho que as predições para novos elementos de grupos já estudados.

Adicionalmente, considerou-se como meta o estudo do desempenho da proposta por meio de simulações; estes estudos de simulação foram implementados com o intuito de que o usuário tome conhecimento da adequabilidade de utilizar o MPE em suas análises, tanto no caso de grupos já analisados quanto para novos grupos.

A título de ilustração da técnica, efetuou-se sua aplicação em dados de saúde hierárquicos com dois níveis. Na primeira aplicação o objetivo é analisar quais características das grávidas e de suas gestações influenciam no peso de recém-nascidos e de que forma estas relações ocorrem. Em seguida, através das informações clínicas de pacientes diagnosticados com periodontite ao longo dos primeiros 12 meses pós-tratamento, deseja-se verificar o sucesso do tratamento, dentre outros aspectos.

\subsection{Contribuições}

Os esforços empregados nesta dissertação tiveram por finalidade apresentar como contribuições principais:

1. o desenvolvimento do método preditivo do melhor preditor empírico para o caso geral, para os efeitos aleatórios e para a média nos modelos beta com intercepto aleatório normal;

2. a avaliação do desempenho da metodologia proposta por meio de estudos de simulação, considerando as predições para elementos pertencentes a grupos que já foram considerados no ajuste e em novos grupos e;

3. a exemplificação do recurso preditivo sugerido através de sua aplicação em duas bases de dados relacionados à saúde.

Como já mencionado neste capítulo, como intuito primário do presente trabalho tem-se a utilização da técnica proposta para a resolução de problemas de análise de dados que requerem da realização de predições em novos grupos e que as variáveis tenham a restrição de estar num intervalo restrito e conhecido, possibilitando a tomada de decisões.

\subsection{Organização do Trabalho}

A presente dissertação é composta por seis capítulos. Uma breve descrição do contexto e dos objetivos do trabalho são apresentados no capítulo 1 . 
O capítulo 2 consiste em revisões de tópicos e conceitos estatísticos necessários ao desenvolvimento do objetivo proposto. O capítulo 3 tem por finalidade apresentar ao leitor a contribuição principal deste trabalho: o melhor preditor de Bayes empírico para a classe de modelos em estudo.

No capítulo 4 encontram-se os esquemas de simulação juntamente com os seus principais resultados com o intuito de verificar o desempenho e a eficácia do preditor proposto. As aplicações estudadas para ilustrar o método, assim como os seus respectivos resultados, encontram-se no capítulo 5 .

Finalizando este trabalho, o capítulo 6 remete o leitor a uma conclusào a respeito de todo o conteúdo desenvolvido ao longo desta dissertação. Este capítulo esclarece, também, sobre possibilidades interessantes de continuação de pesquisas neste tema e área. 


\section{Capítulo 2}

\section{Conceitos}

No presente capítulo tem-se como propósito apresentar ao leitor os principais conceitos de estatística necessários para o entendimento da dissertação. Em especial são apresentados: o modelo de regressão beta com efeito aleatório, a definição do melhor preditor empírico proposto e as medidas de desempenho utilizadas.

\subsection{Distribuição Beta}

A distribuição beta possui diversas parametrizações para sua função densidade de probabilidade. Como neste trabalho ela é aplicada como distribuição da variável resposta no ajuste de modelos de regressão, foram adotadas as parametrizações descritas abaixo.

A função densidade de probabilidade da parametrização considerada por Ferrari e Cribari-Neto (2004) é dada por:

$$
f(y ; \mu, \phi)=\frac{\Gamma(\phi)}{\Gamma(\phi \mu) \Gamma(\phi(1-\mu))} y^{(\mu \phi-1)}(1-y)^{[(1-\mu) \phi-1]},
$$

em que:

- $0<\mathrm{y}<1$

- $0<\mu<1$;

- $\phi>0$

- $\mathrm{E}(\mathrm{Y})=\mu$;

- $\operatorname{Var}(\mathrm{Y})=\frac{\mu(1-\mu)}{1+\phi}=\frac{V(\mu)}{1+\phi}$, onde $V(\mu)=\mu(1-\mu)$.

Nesta parametrização, $\mu$ e $\phi$ são, respectivamente, parâmetros de média e precisão.

A parametrização apresentada em Cribari-Neto e Souza (2012) difere da apresentada anteriormente ao utilizar o parâmetro de dispersão $(\sigma)$ ao invés do parâmetro de precisão $(\phi)$; assim, a 
função densidade de probabilidade dada em termos do parâmetro de dispersão $\sigma$ pode ser expressa como:

$$
f(y ; \mu, \sigma)=\frac{\Gamma\left(\left(1-\sigma^{2}\right) / \sigma^{2}\right)}{\Gamma\left(\mu\left(\left(1-\sigma^{2}\right) / \sigma^{2}\right)\right) \Gamma\left((1-\mu)\left(\left(1-\sigma^{2}\right) / \sigma^{2}\right)\right)} y^{\left(\mu\left(\left(1-\sigma^{2}\right) / \sigma^{2}\right)-1\right)}(1-y)^{\left[(1-\mu)\left(\left(1-\sigma^{2}\right) / \sigma^{2}\right)-1\right]},
$$

em que:

- $0<\mathrm{y}<1$;

- $0<\mu<1$;

- $0<\sigma<1$;

- $\mathrm{E}(\mathrm{Y})=\mu$

- $\operatorname{Var}(\mathrm{Y})=\sigma^{2} \mu(1-\mu)=\sigma^{2} \mathrm{~V}(\mu)$.

A relação entre os parâmetros $\sigma$ e $\phi$, respectivamente de dispersão e precisão, ocorre segundo a expressão:

$$
\sigma^{2}=\frac{1}{1+\phi}
$$

Como esta relação é bijetora, todo o conteúdo desta dissertação se aplica a ambas as parametrizações.

A distribuição beta é muito flexível e por esta razão abrange um vasto ramo de aplicações em muitas áreas de análise de dados. Veja na figura 2.1 como sua função densidade de probabilidade se comporta para alguns exemplos de combinações dos parâmetros $(\mu, \phi)$.
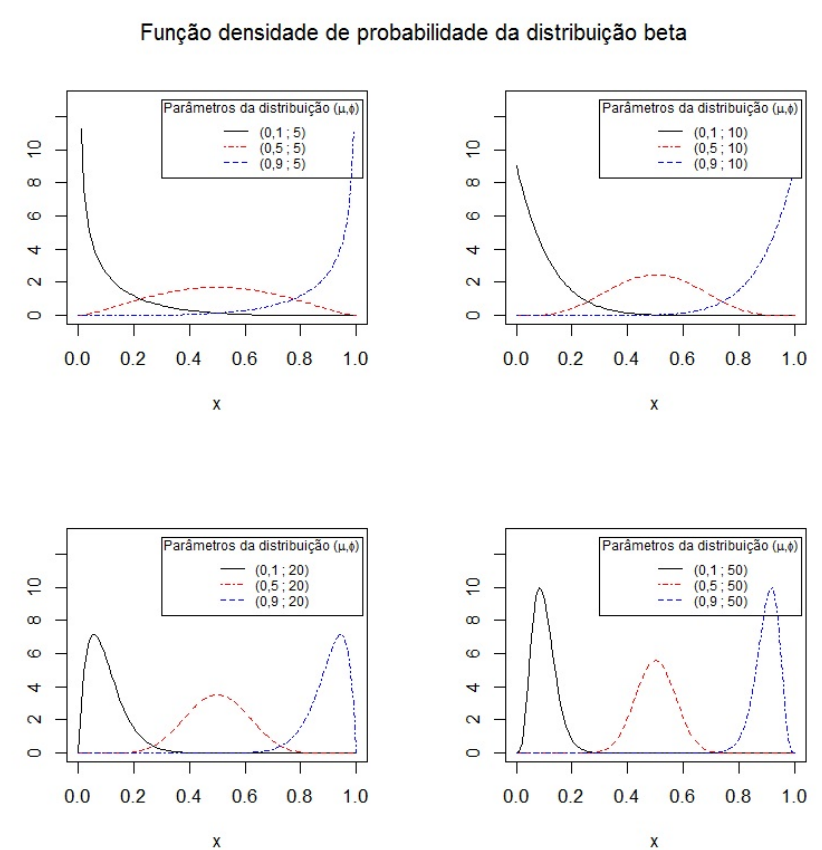

Figura 2.1: Comparação entre as densidades da distribuição beta para diferentes valores dos parâmetros $(\mu, \phi)$. 


\subsection{Modelo de Regressão Beta}

Os modelos de regressão beta têm por finalidade ajustar variáveis contínuas, cujas observações estejam em um intervalo conhecido (a,b); como exemplos de dados que apresentam estas características podem ser citados taxas, proporções, frações, dentre outras.

Em diversas situações, para que seja possível o ajuste de modelos de regressão normal, aplicase uma transformação nos dados. Ao utilizar-se deste procedimento, o pesquisador pode sentir dificuldades de interpretar os resultados do ajuste. Porém, ao considerar que a varíavel resposta do modelo de regressão possui distribuição beta, obtém-se a vantagem de interpretar mais facilmente os resultados do ajuste.

Frequentemente observa-se a aplicação destes modelos em dados assimétricos, em virtude da flexibilidade da distribuição beta, que pode ser verificada, por exemplo, na figura 2.1.

Exemplos de pesquisas relacionadas a estes modelos podem ser encontrados em Paolino (2001), Kieschnick e McCullough (2003), Ferrari e Cribari-Neto (2004), Simas et al. (2010) e Bayes et al. (2012); e para os fins deste trabalho optou-se por considerar os modelos de regressão beta com a parte fixa aos moldes da proposta por Ferrari e Cribari-Neto (2004), os quais utilizam-se da parametrização (2.1) e consideram o ajuste da média da distribuição beta com parâmetro de precisão constante.

Sejam $Y_{1}, \ldots, Y_{n}$ variáveis aleatórias independentes tais que, para $\mathrm{t}=1, \ldots, \mathrm{n}, Y_{t}$ tem distribuição $\operatorname{Beta}\left(\mu_{t}, \phi\right)$, o modelo proposto por Ferrari e Cribari-Neto (2004) pode ser representado por:

$$
g\left(\mu_{t}\right)=\beta_{0}+\sum_{i=1}^{p} x_{t i} \beta_{i}=\eta_{t}
$$

onde:

- $\boldsymbol{\beta}=\left(\beta_{0}, \beta_{1}, \ldots, \beta_{p}\right)^{\prime}$ é o vetor de parâmetros desconhecidos da regressão;

- $x_{t 1}, \ldots, x_{t p}$ são os valores conhecidos das $p$ variáveis explicativas referentes a $t$-ésima observação;

- $g($.$) é a função de ligação estritamente monótona e duplamente diferenciável.$

O modelo apresentado também pode ser ajustado em termos da parametrização (2.2); note que, se considerados constantes, os parâmetros de precisão e dispersão seguem a relação (2.3).

Entretanto, convém relatar ao leitor que Rigby e Stasinopoulos (2005) apresentam, além do modelo de regressão para $\mu_{t}$, a possibilidade de ajustar um modelo de regressão para o parâmetro de dispersão; caso este que não está sendo considerado na presente dissertação.

Outras informações a respeito de modelos de regressão beta podem ser obtidas, por exemplo, no capítulo 3 de Usuga (2013).

\subsection{Dados Correlacionados}

A análise de dados por meio do ajuste de modelos de regressão de efeitos fixos é eficiente e satisfatória em uma diversa gama de estudos; porém, ao assumir a suposição de independência dos 
dados a serem ajustados, esta técnica não se apresenta adequada quando o banco de dados contém algum tipo de correlação.

Pesquisadores de áreas como educação, saúde, marketing, ciências sociais, dentre outras, se interessam em estudar dados que apresentam relações entre si, como por exemplo: desempenho escolar dos alunos de diferentes distritos de uma cidade, resposta ao tratamento de uma doença em pacientes de diferentes unidades hospitalares, dados de pagamento de faturas de cartão de crédito de um mesmo cliente, entre outros exemplos. Nestes casos a suposição de independência dos dados não é satisfeita, pois alunos que possuem mesma professora e/ou escola possuem desempenhos de alguma maneira associados, assim como doentes que receberam o tratamento na mesma unidade hospitalar. Também pode existir relação entre os pagamentos de faturas efetuados ao longo de um período por um mesmo cliente. De forma geral, as unidades de mesmo grupo compartilham características semelhantes e ambientes comuns e, esta característica deve ser levada em consideração ao analisar estes dados.

Bancos de dados que apresentam este tipo de estrutura são usualmente estudados através de modelos mistos. Esta classe de modelos adiciona componentes aleatórios aos modelos com efeitos fixos, possibilitando a incorporação da existência de correlação entre as observações.

Ao longo de todo este trabalho serão considerados como modelos de regressão os modelos mistos. Para mais detalhes sobre esta classe de modelos de forma geral, torna-se interessante a revisão bibliográfica apresentada no segundo capítulo de Hernández (2013).

Um aspecto muito interessante da utilização destes modelos é a possibilidade de incluir variáveis explicativas dos diversos níveis. No caso do estudo do desempenho escolar dos alunos de diferentes distritos de uma cidade, por exemplo, pode-se utilizar como variáveis explicativas:

- características do distrito (renda per capita, indicadores sociais);

- características da escola (avaliação do MEC, orçamento);

- características do professor/classe (tempo de profissão, número de alunos na classe) e;

- características do aluno (grau de escolaridade do pai e/ou da mãe, necessidade de trabalhar pra auxiliar no orçamento familiar).

Inseridos na classe dos dados com dois níveis hierárquicos encontram-se os dados longitudinais; estes são compostos por uma mesma medida observada repetidamente ao longo do tempo. Como exemplos de dados longitudinais tem-se: aferição da pressão arterial sistólica de um mesmo paciente observada em diferentes momentos e umidade do ar nos dias de inverno em uma mesma localidade.

\subsection{Modelo de Regressão Beta com Efeitos Aleatórios}

Nos casos em que os dados a serem ajustados são correlacionados é adequada a inclusão de efeitos aleatórios no modelo; para o caso específico em que a variável resposta possui distribuição 
beta, Figueroa-Zúñiga et al. (2013), Verkuilen e Smithson (2012) e Usuga (2013) estudaram as características deste modelo.

Assim, os modelos de regressão beta com intercepto aleatório normal apresentados por Usuga (2013) são descritos a seguir.

Para $i=1, \ldots, q$ e $j=1, \ldots, n_{i}$, sejam:

- $y_{i j}$ a $j$-ésima observação do $i$-ésimo grupo;

- $\boldsymbol{y}_{i}=\left(y_{i 1}, \ldots, y_{i n_{i}}\right)^{\prime}$ o vetor com as $n_{i}$ observações do $i$-ésimo grupo;

- $Y_{i j} \mid \alpha_{i}$ v.a.'s condicionalmente independentes com distribuição $\operatorname{Beta}\left(\mu_{i j}, \phi\right)$ ou $\operatorname{Beta}\left(\mu_{i j}, \sigma\right)$;

- $\alpha_{1}, \ldots, \alpha_{q}$ v.a.'s independentes com distribuição $\mathrm{N}\left(0, \gamma^{2}\right)$.

O modelo de regressão beta com intercepto aleatório normal é dado por:

$$
g\left(\mu_{i j}\right)=\eta_{i j}=\boldsymbol{x}_{i j}^{\prime} \boldsymbol{\beta}+\alpha_{i}
$$

em que:

- $\boldsymbol{x}_{i j}=\left(1, x_{i j 1}, \ldots, x_{i j p}\right)^{\prime}$ é o vetor com os valores conhecidos das variáveis explicativas para a $j$-ésima observação do $i$-ésimo grupo;

- $\boldsymbol{\beta}=\left(\beta_{0}, \beta_{1}, \ldots, \beta_{p}\right)^{\prime}$ é o vetor de parâmetros fixos da regressão;

- $\alpha_{i}$ é o intercepto aleatório associado ao $i$-ésimo grupo;

- $g($.$) é a função de ligação estritamente monótona e duplamente diferenciável.$

Neste modelo, os estimadores dos parâmetros $\boldsymbol{\beta}, \phi, \sigma$ e $\gamma(\widehat{\boldsymbol{\beta}}, \widehat{\phi}, \widehat{\sigma}$ e $\widehat{\gamma})$ são obtidos pelo método de máxima verossimilhança e não possuem expressões analíticas. Assim, o método numérico de quadratura de Gauss-Hermite apresentado em Liu e Pierce (1994) e Hernández et al. (2013) é sugerido em Usuga (2013) para calcular os estimadores em questão.

Com o intuito de melhor compreender a interpretação e a função do intercepto aleatório no modelo beta misto (2.5), seguem na figura 2.2 dois gráficos, aos moldes da comparação feita em Tamura (2007). Nesta figura tem-se que: em (a) observa-se o modelo de regressão beta de efeitos fixos (2.4) com apenas uma variável explicativa $(p=1)$ e em (b) encontra-se a visualização gráfica do modelo de regressão beta com intercepto aleatório (2.5) também com apenas uma variável explicativa $(p=1)$ e com apenas dois grupos $(q=2)$. 


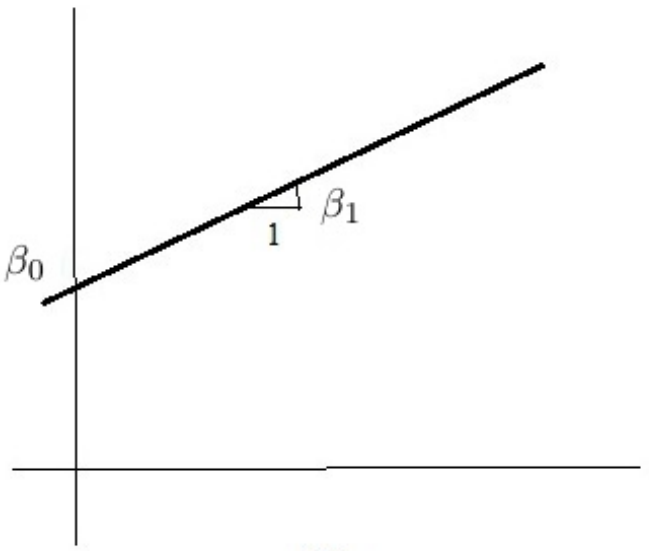

(a)

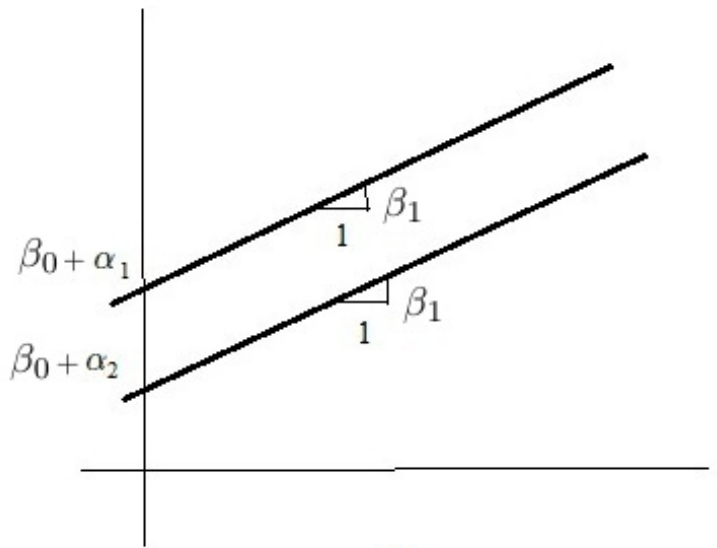

(b)

Figura 2.2: Comparação entre os modelos de regressão beta com efeitos fixos e com intercepto aleatório.

Dessa forma, fica claro pela figura 2.2 que o intercepto aleatório proporciona que o modelo de regressão ajustado caracterize a correlação dos dados ao diferenciar o valor do intercepto para cada grupo $i$, onde $i=1,2, \ldots, q$; mas, note que este modelo mantém sempre o mesmo valor para os coeficientes das variáveis explicativas $(\boldsymbol{\beta})$.

Para o ajuste dos modelos beta mistos e também para efetuar sua análise de diagnóstico, indica-se o uso do software estatístico R, cuja linguagem de programação encontra-se explicada em R Developement Core Team and others (2013). Dentre os pacotes que disponibilizam estes procedimentos estão o gamlss (Generalised Additive Models for Location Scale and Shape) e o blmm. Informações a respeito destes dois pacotes podem ser encontradas, respectivamente, em Stasinopoulos et al. (2008) e em Usuga (2013).

\subsection{Melhor Preditor Empírico}

A predição é uma ferramenta de grande utilidade na atualidade; assim, cada vez mais, técnicas estatísticas vêm sendo desenvolvidas e aprimoradas com o intuito de predizer valores de interesse.

McCulloch et al. (2008) ressalta a diferença das propriedades frequentemente desejadas para a estimação e para a predição: ao se ter interesse na estimação de parâmetros é comum o uso de estimadores não viesados com variância mínima, porém, ao se trabalhar com predições, o usual é considerar métodos que minimizem o erro quadrático médio da predição; este está definido em (2.6) para o preditor $\zeta^{\prime}$ do termo $\zeta$.

$$
E\left(\zeta^{\prime}-\zeta\right)^{2}
$$

Seguindo esta linha de raciocínio, desde os anos 70 vem sendo estudado o método de Bayes empírico, também conhecido por melhor preditor (MP). O MP foi construído de forma a minimizar o erro quadrático médio (2.6) e é uma técnica muito utilizada para predizer valores de efeitos aleatórios nos modelos mistos. 
Dessa forma, baseando-se na esperança a posteriori da variável de interesse para fazer a predição, o MP de um determinado termo $\zeta$ é dado por:

$$
\widetilde{\zeta}=E(\zeta \mid y)
$$

Em McCulloch et al. (2008), os autores desenvolvem no capítulo 13 o MP para os efeitos aleatórios em modelos mistos generalizados, porém, apenas para os casos que os dados ou grupos contribuíram para a estimação dos parâmetros do modelo. Referências interessantes sobre o MP são: Efron e Morris (1973), Morris (1983), Casella (1985), Farrell et al. (1997) e Carlin e Louis (2000).

Para calcular o MP de $\zeta$, conforme a expressão (2.7), é necessário conhecer o valor dos parâmetros do modelo (como detalhadamente evidenciado no capítulo 3), então, como alternativa, foi desenvolvido o melhor preditor empírico (MPE).

O MPE de $\zeta$, denotado por $\widehat{\zeta}$, nada mais é que o melhor preditor de $\zeta(\widetilde{\zeta})$ quando se substitui os parâmetros do modelo por suas respectivas estimativas; ou seja, $\widehat{\zeta}$ é obtido ao substituir os valores dos parâmetros do modelo por suas estimativas na expressão (2.7).

Na literatura especializada em modelos lineares mistos, claramente se observa a predominância do uso da metodologia do melhor preditor empírico para a predição dos efeitos aleatórios; exemplos de autores que confirmam esta afirmação são Fitzmaurice et al. (2008), McCulloch et al. (2008) e Verbeke e Molenberghs (2009).

Quando se tem interesse em predizer valores para elementos de grupos que não foram utilizados no ajuste, como é o caso desta dissertação, foi desenvolvido, baseando-se na proposta de Jiang e Lahiri (2001) e Jiang e Lahiri (2006), em Tamura (2007), em Tamura e Giampaoli (2010), em Tamura (2012) e em Tamura e Giampaoli (2013) o MPE para o modelo logístico misto em diferentes situações de aplicação.

Para os modelos de regressão beta mistos em que o intercepto aleatório segue distribuições normal, log-gama, t-Student ou exponencial-potência, Usuga (2013) desenvolveu o MPE do intercepto aleatório apenas para os grupos que compõem a amostra utilizada no ajuste do modelo. O MPE desenvolvido na referência anteriormente citada pode ser calculado através da função re.prediction do pacote blmm do software R.

\subsection{Medidas de Avaliação de Desempenho}

As medidas de avaliação de desempenho possuem importância considerável na estatística pois permitem, dentre outros, avaliar determinados aspectos da qualidade de estimadores e preditores, como ressalta Steyeberg et al. (2010).

Em situações em que o objetivo é analisar a eficácia de preditores de quantidades contínuas, dentre as diversas opções propostas na literatura, encontram-se a raíz do erro quadrático médio de predição (REQMP), o viés relativo médio e os resíduos quantílicos aleatorizados. 
Com o intuito de analisar o desempenho do MPE desenvolvido na seção 3.3 nos estudos de simulação que serão apresentados mais adiante, foram utilizadas as medidas de desempenho descritas nesta seção.

\subsubsection{Raíz do erro quadrático médio de predição}

Assim como utilizado em McCulloch e Neuhaus (2011), o erro quadrático médio de predição (EQMP) do preditor $\widehat{\zeta}$ é calculado com a equação (2.8).

$$
\operatorname{EQMP}(\widehat{\zeta})=\frac{\sum_{k=1}^{N} \sum_{i=1}^{q} \sum_{j=1}^{n_{i}}\left(\widehat{\zeta}_{i j k}-\zeta_{i j k}\right)^{2}}{N \sum_{i=1}^{q} n_{i}},
$$

em que:

- N é o número de réplicas da simulação;

- $q$ é o número de grupos do banco de dados;

- $n_{i}$ é o número de elementos do $i$-ésimo grupo;

- $\zeta_{i j k}$ é o valor verdadeiro do termo que se deseja estudar (possui valor conhecido nos estudos de simulação) para o elemento $j$ do $i$-ésimo grupo na $k$-ésima réplica e;

- $\widehat{\zeta}_{i j k}$ é o MPE contabilizado do termo que se deseja inferir para o elemento $j$ do $i$-ésimo grupo na $k$-ésima réplica.

A raíz do erro quadrático médio de predição (REQMP) é calculada aplicando-se a raíz quadrada no valor obtido na equação (2.8). O uso da REQMP ao invés do EQMP é mais frequente por ela se apresentar na mesma medida do termo em estudo, e por este mesmo motivo foi decidido utilizá-la nesta dissertação.

A REQMP foi analisada nos estudos de simulação de forma a compreender o seu comportamento quando os valores dos parâmetros envolvidos nestes estudos são variados. Assim, tem-se que esta quantidade foi interpretada através de comparações de seus valores para cada um dos cenários.

\subsubsection{Viés relativo médio}

O viés relativo médio (vrm) é uma medida de acurácia interessante, pois possibilita a visualização dos erros de predição em termos da proporção destes erros em relação ao verdadeiro valor do item predito.

Assim como considerado em Sheiner e Beal (1981), esta medida de performance foi calculada para este trabalho segundo a equação (2.9).

$$
\operatorname{vrm}(\widehat{\zeta})=\frac{1}{N \sum_{i=1}^{q} n_{i}} \sum_{k=1}^{N} \sum_{i=1}^{q} \sum_{j=1}^{n_{i}}\left(\frac{\widehat{\zeta}_{i j k}-\zeta_{i j k}}{\zeta_{i j k}}\right),
$$

cujas notações, definições e nomenclaturas são iguais às apresentadas para a REQMP no item anterior (2.6.1). 
Nos estudos de simulação, o viés relativo médio foi analisado comparando-se seus valores ao variar os parâmetros envolvidos no estudo. Com estas análises, deseja-se conhecer o comportamento do viés relativo nas diferentes situações de aplicação do método.

\subsubsection{Resíduo quantílico aleatorizado}

A adequabilidade de ajustes de modelos de regressão normal é facilmente analisada por meio dos resíduos da regressão, pois a distribuição destes erros é conhecida. Entretanto, o mesmo não ocorre com modelos cuja variável resposta não é normalmente distribuída.

O resíduo quantílico aleatorizado (normalizado) foi introduzido por Dunn e Smyth (1996) e é definido como:

$$
r_{q, i j}=\Phi^{-1}\left\{F\left(y_{i j} ; \widehat{\mu}_{i j}, \phi\right)\right\}
$$

em que da mesma forma:

- $i=1, \ldots, q$ é a referência ao grupo;

- $j=1, \ldots, n_{i}$ se refere ao $j$-ésimo elemento do grupo $i$;

- $\Phi($.$) é a função de distribuição acumulada da normal padrão;$

- $\widehat{\mu}_{i j}$ denota a estimativa de $\mu_{i j}$ e;

- $F\left(y_{i j} ; \widehat{\mu}_{i j}, \phi\right)$ é a função de distribuição acumulada da distribuição $\operatorname{Beta}\left(\widehat{\mu}_{i j}, \phi\right)$.

De acordo com sua definição, quando as suposições do modelo são satisfeitas, estes resíduos deveriam ser normalmente distribuídos em caso de adequabilidade da predição ou do ajuste, conforme explica Rigby e Stasinopoulos (2005).

Com isso, a utilização destes resíduos é vantajosa por ele possuir distribuição conhecida independente da distribuição da variável resposta e porque sua distribuição é fácil de ser checada por meio de testes de hipóteses e gráficos normais de probabilidade (QQ-plot).

Então, fazendo uso do gráfico QQ-plot, para que o MPE seja apontado como adequado, esperase que os resíduos quantílicos aleatorizados disponibilizados no gráfico estejam próximos da reta, ou seja, tenham distribuição normal. 


\section{Capítulo 3}

\section{Predição nos Modelos de Regressão Beta com Intercepto Aleatório}

Este capítulo apresenta a contribuição principal desta dissertação: o desenvolvimento de um método de predição para funções do intercepto aleatório nos modelos de regressão beta com intercepto aleatório normal.

Esta metodologia é versátil por ser possível de ser aplicada em duas ocasiões: (1) quando o pesquisador possui um banco de dados composto por $g$ grupos e, baseado nas informações destes dados, ele deseja fazer a predição para um novo elemento pertencente a algum destes $g$ grupos que foram analisados na base dados e, (2) quando o pesquisador possui um banco de dados inicial com $g$ grupos e, baseado nestes dados, ele tem interesse em obter as predições de novos elementos que não pertencem a nenhum destes $g$ grupos.

Para melhor esclarecimento, considere o exemplo do estudo do desempenho escolar de alunos de diferentes escolas de uma cidade; neste exemplo o pesquisador pode estar interessado em predizer tanto o desempenho de um novo aluno de uma escola já estudada, na qual se matriculou recentemente e ainda não passou por avaliações, quanto o desempenho de alunos de uma escola que ainda não foi avaliada pelo pesquisador.

Neste capítulo, inicialmente, serão expostas ao leitor definições e notações necessárias ao entendimento do conteúdo a ser apresentado.

\subsection{Caso geral}

\subsubsection{Notações e definições}

A seguir são apresentadas as notações e os conceitos necessários para o entendimento do método proposto.

- $i$ é o índice relacionado ao nível mais alto da hierarquia, como por exemplo: o hospital no qual os pacientes foram tratados ou o indivíduo cujas aferições de pressão sistólica foram medidas em diferentes momentos;

- $q$ é o número de elementos que compõem o nível explicado no ítem acima; dessa forma, $i=1,2, \ldots, q$; 
- $j$ é o índice relacionado ao segundo nível da hierarquia, ou seja, ele identifica elementos do grupo $i$. Nos exemplos ele representa qual paciente do hospital $i$ se está mencionando, ou em qual momento foi medida a pressão sistólica de determinado paciente $i$;

- $j=1,2, \ldots, n_{i}$, pois os grupos podem possuir números diferentes de elementos $\left(n_{i}\right)$;

- $y_{i j}$ é a $j$-ésima observação da variável resposta do $i$-ésimo grupo;

- $\boldsymbol{y}_{i}=\left(y_{i 1}, \ldots, y_{i n_{i}}\right)^{\prime}$ é o vetor com as $n_{i}$ observações da variável resposta do $i$-ésimo grupo;

- $Y_{i j} \mid \alpha_{i}$ são v.a.'s condicionalmente independentes com distribuição $\operatorname{Beta}\left(\mu_{i j}, \phi\right) \operatorname{ou} \operatorname{Beta}\left(\mu_{i j}, \sigma\right)$;

- $\alpha_{1}, \ldots, \alpha_{q}$ são os interceptos aleatórios dos $q$ grupos; eles são v.a.'s independentes com distribuição $\mathrm{N}\left(0, \gamma^{2}\right)$;

- $\boldsymbol{x}_{i j}=\left(1, x_{i j 1}, \ldots, x_{i j p}\right)^{\prime}$ é o vetor com os valores conhecidos das variáveis explicativas para a $j$-ésima observação do $i$-ésimo grupo;

- $\boldsymbol{\beta}=\left(\beta_{0}, \beta_{1}, \ldots, \beta_{p}\right)^{\prime}$ é o vetor de parâmetros fixos da regressão;

- $g($.$) é a função de ligação estritamente monótona e duplamente diferenciável;$

- o modelo a ser considerado é dado pela equação (2.5), cuja expressão é dada por:

$$
g\left(\mu_{i j}\right)=\eta_{i j}=\boldsymbol{x}_{i j}^{\prime} \boldsymbol{\beta}+\alpha_{i}
$$

- $\widehat{\gamma}, \widehat{\boldsymbol{\beta}}$ e $\widehat{\phi}$ são as respectivas estimativas de máxima verossimilhança dos parametros $\gamma, \boldsymbol{\beta}$ e $\phi$. Estas estimativas são calculadas com os dados de parte dos $q$ grupos que compõem o banco de dados, que será chamada de base de ajuste (BA);

- $\zeta=\zeta\left(\boldsymbol{\beta}, \alpha_{i}\right)$ é o termo que se tem interesse em predizer;

- o MP de $\zeta$, definido anteriormente na seção 2.5, é denotado por $\widetilde{\zeta}$;

- o MPE de $\zeta$, definido anteriormente na seção 2.5, é denotado por $\widehat{\zeta}$.

\subsubsection{MPE para o caso geral}

Assim como explicado na seção 2.5, o MP se baseia na minimização do EQMP. A expressão que o define, como exposto na equação (2.7), é dada por: $\widetilde{\zeta}=E(\zeta \mid \boldsymbol{y})$; para maiores detalhes indica-se a leitura de Jiang e Lahiri (2006) e Tamura (2012). Os passos para o desenvolvimento desta expressão encontram-se nas linhas abaixo.

$$
\begin{gathered}
\tilde{\zeta}=E\left[\zeta\left(\boldsymbol{\beta}, \alpha_{i}\right) \mid \boldsymbol{y}_{\boldsymbol{i}}\right] \\
=\int \zeta\left(\boldsymbol{\beta}, \alpha_{i}\right) f\left(\alpha_{i} \mid \boldsymbol{y}_{\boldsymbol{i}}\right) d \alpha_{i} \\
=\int \zeta\left(\boldsymbol{\beta}, \alpha_{i}\right) \frac{f\left(\boldsymbol{y}_{\boldsymbol{i}}, \alpha_{i}\right)}{f\left(\boldsymbol{y}_{\boldsymbol{i}}\right)} d \alpha_{i}
\end{gathered}
$$




$$
\begin{gathered}
=\int \zeta\left(\boldsymbol{\beta}, \alpha_{i}\right) \frac{f\left(\boldsymbol{y}_{\boldsymbol{i}} \mid \alpha_{i}\right) f_{\alpha}\left(\alpha_{i}\right)}{f\left(\boldsymbol{y}_{\boldsymbol{i}}\right)} d \alpha_{i} \\
=\frac{1}{f\left(\boldsymbol{y}_{\boldsymbol{i}}\right)} \int \zeta\left(\boldsymbol{\beta}, \alpha_{i}\right) f\left(\boldsymbol{y}_{\boldsymbol{i}} \mid \alpha_{i}\right) f_{\alpha}\left(\alpha_{i}\right) d \alpha_{i} \\
=\frac{\int \zeta\left(\boldsymbol{\beta}, \alpha_{i}\right) f\left(\boldsymbol{y}_{\boldsymbol{i}} \mid \alpha_{i}\right) f_{\alpha}\left(\alpha_{i}\right) d \alpha_{i}}{\int f\left(\boldsymbol{y}_{\boldsymbol{i}}, \alpha_{i}\right) d \alpha_{i}} \\
=\frac{\int \zeta\left(\boldsymbol{\beta}, \alpha_{i}\right) f\left(\boldsymbol{y}_{\boldsymbol{i}} \mid \alpha_{i}\right) f_{\alpha}\left(\alpha_{i}\right) d \alpha_{i}}{\int f\left(\boldsymbol{y}_{\boldsymbol{i}} \mid \alpha_{i}\right) f_{\alpha}\left(\alpha_{i}\right) d \alpha_{i}}
\end{gathered}
$$

A partir deste ponto, detalha-se os cálculos para o caso específico em que a variável resposta possui distribuição beta. Podem ser consideradas ambas as parametrizações (2.1) e (2.2), porém, neste caso será utilizada a parametrização (2.1) em termos da precisão.

Novamente ressalta-se que como a relação entre $\phi$ e $\sigma$ é bijetora, para o caso que está sendo considerado, pode-se obter os mesmos resultados para a parametrização em termos da dispersão (2.2) ao utilizar a relação (2.3).

Assim, de acordo com as definições dadas, tem-se que:

$$
\begin{gathered}
f\left(\boldsymbol{y}_{i} \mid \alpha_{i}\right)=f\left(y_{i 1}, y_{i 2}, \ldots, y_{i n_{i}} \mid \alpha_{i}\right)=\prod_{j=1}^{n_{i}} f\left(y_{i j} \mid \alpha_{i}\right) \\
=\prod_{j=1}^{n_{i}}\left\{\frac{\Gamma(\phi)}{\Gamma\left(\phi \mu_{i j}\right) \Gamma\left(\phi\left(1-\mu_{i j}\right)\right)} y_{i j}{ }^{\left(\mu_{i j} \phi-1\right)}\left(1-y_{i j}\right)^{\left[\left(1-\mu_{i j}\right) \phi-1\right]}\right\} \\
=\Gamma(\phi)^{n_{i}} \prod_{j=1}^{n_{i}}\left\{\frac{1}{\Gamma\left(\phi \mu_{i j}\right) \Gamma\left(\phi\left(1-\mu_{i j}\right)\right)}\left(\frac{y_{i j}}{1-y_{i j}}\right)^{\left(\phi \mu_{i j}\right)} \frac{\left(1-y_{i j}\right)^{(\phi-1)}}{y_{i j}}\right\} \\
=\Gamma(\phi)^{n_{i}} \prod_{j=1}^{n_{i}}\left\{\frac{\left(1-y_{i j}\right)^{(\phi-1)}}{y_{i j}}\right\} R_{i}\left(\boldsymbol{\beta}, \alpha_{i}, \phi\right),
\end{gathered}
$$

em que:

$$
R_{i}\left(\boldsymbol{\beta}, \alpha_{i}, \phi\right)=\prod_{j=1}^{n_{i}}\left\{\frac{1}{\Gamma\left(\phi \mu_{i j}\right) \Gamma\left(\phi\left(1-\mu_{i j}\right)\right)}\left(\frac{y_{i j}}{1-y_{i j}}\right)^{\left(\phi \mu_{i j}\right)}\right\} .
$$

Note que o efeito aleatório $\alpha_{i}$ está implícito em (3.3) pelas relações dadas em (2.5).

Dessa forma, substituindo-se a expressão (3.2) em (3.1) tem-se que:

$$
\widetilde{\zeta}=\frac{\Gamma(\phi)^{n_{i}}}{\Gamma(\phi)^{n_{i}}} \frac{\prod_{j=1}^{n_{i}}\left\{\frac{\left(1-y_{i j}\right)^{(\phi-1)}}{y_{i j}}\right\}}{\prod_{j=1}^{n_{i}}\left\{\frac{\left(1-y_{i j}\right)^{(\phi-1)}}{y_{i j}}\right\}} \frac{\int \zeta\left(\boldsymbol{\beta}, \alpha_{i}\right) R_{i}\left(\boldsymbol{\beta}, \alpha_{i}, \phi\right) f_{\alpha}\left(\alpha_{i}\right) d \alpha_{i}}{\int R_{i}\left(\boldsymbol{\beta}, \alpha_{i}, \phi\right) f_{\alpha}\left(\alpha_{i}\right) d \alpha_{i}}
$$




$$
\begin{gathered}
=\frac{\int \zeta\left(\boldsymbol{\beta}, \alpha_{i}\right) R_{i}\left(\boldsymbol{\beta}, \alpha_{i}, \phi\right) f_{\alpha}\left(\alpha_{i}\right) d \alpha_{i}}{\int R_{i}\left(\boldsymbol{\beta}, \alpha_{i}, \phi\right) f_{\alpha}\left(\alpha_{i}\right) d \alpha_{i}} \\
=\frac{E\left[\zeta\left(\boldsymbol{\beta}, \alpha_{i}\right) R_{i}\left(\boldsymbol{\beta}, \alpha_{i}, \phi\right)\right]}{E\left[R_{i}\left(\boldsymbol{\beta}, \alpha_{i}, \phi\right)\right]} .
\end{gathered}
$$

Considerando o caso em que o intercepto aleatório é normalmente distribuído, será feito o uso da substituição deste termo na expressão (3.4) de acordo com a relação a seguir.

$$
\alpha_{i}=\gamma \xi, \quad \text { em que } \xi \text { tem distribuição } \mathrm{N}(0,1)
$$

Desta relação verifica-se que:

- $f_{\alpha}\left(\alpha_{i}\right)=f_{\alpha}(\gamma \xi)=\frac{1}{\sqrt{2 \pi \gamma^{2}}} \exp \left\{\frac{-(\gamma \xi)^{2}}{2 \gamma^{2}}\right\}=\frac{1}{\gamma}\left[\frac{1}{\sqrt{2 \pi}} \exp \left(\frac{-\xi^{2}}{2}\right)\right]=\frac{1}{\gamma} f_{\xi}(\xi)$;

- $d \alpha_{i}=\gamma d \xi$

- os intervalos de integração de ambas as integrais de (3.4) permanecem os mesmos ao aplicar a transformação de variáveis.

Logo, ao aplicar os resultados acima, tem-se que (3.4) pode ser expressada como:

$$
\begin{gathered}
\frac{\int \zeta\left(\boldsymbol{\beta}, \alpha_{i}\right) R_{i}\left(\boldsymbol{\beta}, \alpha_{i}, \phi\right) f_{\alpha}\left(\alpha_{i}\right) d \alpha_{i}}{\int R_{i}\left(\boldsymbol{\beta}, \alpha_{i}, \phi\right) f_{\alpha}\left(\alpha_{i}\right) d \alpha_{i}}=\frac{\int \zeta(\boldsymbol{\beta}, \gamma \xi) R_{i}(\boldsymbol{\beta}, \gamma \xi, \phi) \frac{1}{\gamma} f_{\xi}(\xi) \gamma d \xi}{\int R_{i}(\boldsymbol{\beta}, \gamma \xi, \phi) \frac{1}{\gamma} f_{\xi}(\xi) \gamma d \xi} \\
=\frac{\int \zeta(\boldsymbol{\beta}, \gamma \xi) R_{i}(\boldsymbol{\beta}, \gamma \xi, \phi) f_{\xi}(\xi) d \xi}{\int R_{i}(\boldsymbol{\beta}, \gamma \xi, \phi) f_{\xi}(\xi) d \xi} \\
=\frac{E\left[\zeta(\boldsymbol{\beta}, \gamma \xi) R_{i}(\boldsymbol{\beta}, \gamma \xi, \phi)\right]}{E\left[R_{i}(\boldsymbol{\beta}, \gamma \xi, \phi)\right]}
\end{gathered}
$$

Até o presente momento trabalhou-se com os valores verdadeiros dos parâmetros, porém na realidade eles são desconhecidos. Este é o ponto em que o MP e o MPE se diferenciam, já que a transição do primeiro para o segundo ocorre ao substituir-se em (3.6) os parâmetros $\gamma, \boldsymbol{\beta}$ e $\phi$ pelos seus respectivos valores estimados $\widehat{\gamma}, \widehat{\boldsymbol{\beta}}$ e $\widehat{\phi}$.

Portanto, o MPE de $\zeta$ é definido como:

$$
\begin{gathered}
\widehat{\zeta}=\widetilde{\zeta}(\widehat{\boldsymbol{\beta}}, \widehat{\gamma} \xi) \\
=\frac{\int\left[\zeta(\widehat{\boldsymbol{\beta}}, \widehat{\gamma} \xi) R_{i}(\widehat{\boldsymbol{\beta}}, \widehat{\gamma} \xi, \widehat{\phi}) f_{\xi}(\xi)\right] d \xi}{\int\left[R_{i}(\widehat{\boldsymbol{\beta}}, \widehat{\gamma} \xi, \widehat{\phi}) f_{\xi}(\xi)\right] d \xi} \\
=\frac{E\left[\zeta(\widehat{\boldsymbol{\beta}}, \widehat{\gamma} \xi) R_{i}(\widehat{\boldsymbol{\beta}}, \widehat{\gamma} \xi, \widehat{\phi})\right]}{E\left[R_{i}(\widehat{\boldsymbol{\beta}}, \widehat{\gamma} \xi, \widehat{\phi})\right]} .
\end{gathered}
$$


Observa-se em (3.8) que o MPE é composto por integrais que não possuem solução explícita. Portanto, é necessário o uso de métodos numéricos para calculá-lo. Ao longo de toda a dissertação fez-se o uso da quadratura de Gauss-Hermite para esta finalidade. Detalhes da quadratura de Gauss-Hermite são encontradas, por exemplo, em Liu e Pierce (1994) e Hernández et al. (2013).

Repare que em (3.3) se faz necessário conhecer o valor das variáveis respostas observadas $\left(y_{i j}\right)$. Quando o grupo alvo para predição integra o banco de dados utilizado para ajustar o modelo e estimar os parâmetros $\gamma, \boldsymbol{\beta}$ e $\phi$, estes valores são conhecidos. Todavia, o grande diferencial desta técnica proposta é possibilitar a predição para os grupos que não contribuíram para o ajuste do modelo, aqui denominados novos grupos; e nestes casos os valores de $y_{i j}$ não são conhecidos.

Com isso, dentre as várias possibilidades de substituição de $y_{i j}$, ao longo da dissertação, os cálculos efetuaram-se segundo as etapas:

1. ajustou-se o modelo de regressão beta com efeitos fixos (2.4) para a mesma base de dados considerada no ajuste do modelo beta misto (base de ajuste). Para tal, fez-se uso do pacote betareg do software $\mathrm{R}$ (informações sobre este pacote podem ser encontradas em Cribari-Neto e Zeileis (2010) e Grün et al. (2012));

2. dadas as estimativas obtidas, fez-se a predição de $E\left(Y_{i j}\right)$ através do modelo beta com efeitos fixos para os elementos dos novos grupos (não pertencentes a base de ajuste); isto é possível pois os valores das covariáveis do modelo são conhecidos para estes elementos que se tem interesse em estudar;

3. substitui-se o valor $y_{i j}$ pelo valor predito de $E\left(Y_{i j}\right)$ obtido no passo 2 e;

4. depois se procedem os cálculos como no outro caso.

\subsection{MPE do intercepto aleatório}

Para o caso específico em que se tem interesse em predizer o intercepto aleatório de determinado grupo $i$, tem-se que o termo $\zeta=\alpha_{i}$. Ao substituir em (3.9) o termo $\zeta$, conclui-se que o MPE para o intercepto aleatório do $i$-ésimo grupo é dado por:

$$
\begin{aligned}
\widehat{\zeta} & =\widehat{\alpha}_{i}=\frac{E\left[\widehat{\gamma} \xi R_{i}(\widehat{\boldsymbol{\beta}}, \widehat{\gamma} \xi, \widehat{\phi})\right]}{E\left[R_{i}(\widehat{\boldsymbol{\beta}}, \widehat{\gamma} \xi, \widehat{\phi})\right]} \\
& =\frac{\widehat{\gamma} E\left[\xi R_{i}(\widehat{\boldsymbol{\beta}}, \widehat{\gamma} \xi, \widehat{\phi})\right]}{E\left[R_{i}(\widehat{\boldsymbol{\beta}}, \widehat{\gamma} \xi, \widehat{\phi})\right]} .
\end{aligned}
$$

Adicionalmente, assinala-se que em (3.9), o cálculo de $\widehat{\mu}_{i j}$ no termo $R_{i}(\widehat{\boldsymbol{\beta}}, \widehat{\gamma} \xi, \widehat{\phi})$ se dá conforme a relação: $\widehat{\mu}_{i j}=g^{-1}\left(\widehat{\eta}_{i j}\right)=g^{-1}\left(\boldsymbol{x}_{i j}^{\prime} \widehat{\boldsymbol{\beta}}+\widehat{\gamma} \xi\right)$. 


\subsection{MPE de $E\left(Y_{i j} \mid \alpha_{i}\right)$}

Observa-se que, na maioria das aplicações o termo que se tem interesse em predizer é a média da distribuição de $Y_{i j}$ dado $\alpha_{i}$, ou seja, $\mu_{i j}$.

Dessa forma, esta seção tem o propósito de apresentar o MPE para $\mu_{i j}=E\left(Y_{i j} \mid \alpha_{i}\right)$, desenvolvendo a expressão (3.8), como segue abaixo:

$$
\begin{gathered}
\widehat{\zeta}=\frac{\int\left[g^{-1}\left(\widehat{\eta}_{i j}\right) R_{i}(\widehat{\boldsymbol{\beta}}, \widehat{\gamma} \xi, \widehat{\phi}) f_{\xi}(\xi)\right] d \xi}{\int\left[R_{i}(\widehat{\boldsymbol{\beta}}, \widehat{\gamma} \xi, \widehat{\phi}) f_{\xi}(\xi)\right] d \xi} \\
=\frac{\int\left[g^{-1}\left(\boldsymbol{x}_{i j}^{\prime} \widehat{\boldsymbol{\beta}}+\widehat{\gamma} \xi\right) R_{i}(\widehat{\boldsymbol{\beta}}, \widehat{\gamma} \xi, \widehat{\phi}) f_{\xi}(\xi)\right] d \xi}{\int\left[R_{i}(\widehat{\boldsymbol{\beta}}, \widehat{\gamma} \xi, \widehat{\phi}) f_{\xi}(\xi)\right] d \xi} .
\end{gathered}
$$

Adicionalmente, podemos expressar a equação (3.11) como:

$$
\widehat{\zeta}=\frac{E\left[g^{-1}\left(\boldsymbol{x}_{i j}^{\prime} \widehat{\boldsymbol{\beta}}+\widehat{\gamma} \xi\right) R_{i}(\widehat{\boldsymbol{\beta}}, \widehat{\gamma} \xi, \widehat{\phi})\right]}{E\left[R_{i}(\widehat{\boldsymbol{\beta}}, \widehat{\gamma} \xi, \widehat{\phi})\right]} .
$$

Para o caso específico em que a função de ligação $g($.$) de interesse é a logito, tem-se por definição$ que $\eta_{i j}=g\left(\mu_{i j}\right)=\log \left(\frac{\mu_{i j}}{1-\mu_{i j}}\right)$; logo, para obter a expressão do MPE neste caso, substitui-se em (3.11) o termo $g^{-1}\left(\widehat{\eta}_{i j}\right)$ por $\left(\frac{e^{\widehat{\eta}_{i j}}}{1+e^{\hat{\eta}_{i j}}}\right)$.

Assim, após efetuada a substituição, o MPE de $\zeta=\mu_{i j}$ ao utilizar-se da ligação logito, é dado por:

$$
\widehat{\zeta}=\frac{\int\left[\frac{e^{\hat{\vartheta}_{i j}}}{1+e^{\hat{\vartheta}_{i j}}} R_{i}(\widehat{\boldsymbol{\beta}}, \widehat{\gamma} \xi, \widehat{\phi}) f_{\xi}(\xi)\right] d \xi}{\int\left[R_{i}(\widehat{\boldsymbol{\beta}}, \widehat{\gamma} \xi, \widehat{\phi}) f_{\xi}(\xi)\right] d \xi}=\frac{E\left[\left(\frac{e^{\hat{\eta}_{i j}}}{1+e^{\hat{\vartheta}_{i j}}}\right) R_{i}(\widehat{\boldsymbol{\beta}}, \widehat{\gamma} \xi, \widehat{\phi})\right]}{E\left[R_{i}(\widehat{\boldsymbol{\beta}}, \widehat{\gamma} \xi, \widehat{\phi})\right]},
$$

em que $\widehat{\eta}_{i j}=\boldsymbol{x}_{i j}^{\prime} \widehat{\boldsymbol{\beta}}+\widehat{\gamma} \xi$.

Note que tendo em mãos o MPE do efeito aleatório $\left(\widehat{\alpha}_{i}\right)$, pode-se utilizá-lo para estimar a média $\left(\mu_{i j}\right)$ por meio da expressão abaixo:

$$
g^{-1}\left(\boldsymbol{x}_{i j}^{\prime} \widehat{\boldsymbol{\beta}}+\widehat{\alpha}_{i}\right)
$$

Porém, optou-se por desenvolver o melhor preditor empírico especificamente para a média, cuja expressão encontra-se em (3.11), pois seu erro quadrático médio é menor que o do preditor (3.14).

Além disso, o preditor (3.14) leva em consideração as informações dos dados apenas no cálculo do valor predito do efeito aleatório, enquanto o MPE de $\mu_{i j}$ as utiliza em sua fórmula relacionandoas a todo o modelo. 
Dando continuação aos estudos, após o desenvolvimento do método e apresentação das expressões resultantes, no capítulo adiante seguem os estudos de simulação construídos de forma a averiguar o desempenho preditivo do método aqui proposto. 


\section{Capítulo 4}

\section{Estudo de Simulação}

Os estudos de simulação são assiduamente utilizados em estatística por permitirem aos pesquisadores conhecer o desempenho de suas ferramentas (estimadores, testes de hipóteses, preditores, etc.) em situações diversas. Portanto, simulando dados, o pesquisador explora as propriedades de seu método e ilustra ao leitor os resultados esperados em sua aplicação.

Neste capítulo, os estudos têm o intuito de verificar o desempenho do método de predição proposto. Eles foram analisados em duas partes: primeiramente, dado que as suposições do intercepto aleatório do modelo são satisfeitas, investigou-se se as predições do MPE para $\alpha_{1}, \alpha_{2}, \ldots, \alpha_{q}$ continuam satisfazendo as suposições consideradas; em seguida, tomando como base as medidas de desempenho expostas na seção 2.6, averiguou-se a performance do MPE para a média.

Também foram concentrados esforços em explorar se existem diferenças de desempenho entre predições efetuadas para elementos de grupos incorporados à base de ajuste e predições de elementos de novos grupos. Espera-se observar desempenhos semelhantes para que esta ferramenta permita inferências confiáveis aos pesquisadores que a utilizarem em ambas as situações.

\subsection{Objetivos}

Todo o estudo de simulação apresentado foi delineado com o objetivo de analisar a performance do MPE em dois aspectos: inicialmente, tem-se o interesse de conhecer quais das suposições do intercepto aleatório do modelo (2.5) são satisfeitas para as predições destes termos por meio do método preditivo apresentado anteriormente na seção 3.2. Adicionalmente, os esforços se concentraram em explorar o desempenho do melhor preditor empírico para a média, o qual encontra-se exposto na seção 3.3 .

Para tal, o banco de dados simulado foi dividido em duas partes. A primeira, denominada base de ajuste (BA), é a base considerada para estimação dos parâmetros do modelo de regressão beta misto necessários ao cálculo do MPE; a segunda, denominada base de predição (BP), é composta pelos dados dos novos grupos, e não foi considerada afins de ajustar o modelo.

A intenção principal desta dissertação é possibilitar aos pesquisadores uma ferramenta de predição que seja tão eficiente para novos grupos quanto o é para a BA. Com isso, explorou-se todo o desempenho do MPE separadamente para os dados da BA e da BP; dessa forma torna-se possível entender o quão semelhantes estes desempenhos são. 


\subsubsection{Objetivos das simulações do MPE para o intercepto aleatório}

Para o modelo (2.5) em questão, supõe-se que:

1. $\alpha_{1}, \alpha_{2}, \ldots, \alpha_{q}$ sejam independentes;

2. $\alpha_{i}$ seja normalmente distribuído para todo $i=1,2, . ., q$;

3. $E\left(\alpha_{i}\right)=0$ para todo $i=1,2, . ., q$;

4. $\operatorname{Var}\left(\alpha_{i}\right)=\gamma^{2}$ para todo $i=1,2, . ., q$.

Um dos escopos deste capítulo é investigar se as suposições 2, 3 e 4 permanecem válidas para as predições dos interceptos aleatórios. O método utilizado para averiguar este aspecto é a aplicação de testes de hipóteses adequados à cada suposição em estudo.

Para tal, foram selecionados três testes de hipóteses para inferir a respeito das hipóteses que se deseja analisar. A seguir estes testes são apresentados e as formas de aplicação deles são explicadas, mas, já se adianta que em todos eles, para considerar as suposições 2, 3 e 4 como sendo satisfeitas, deseja-se que nenhum dos três testes de hipóteses empregados rejeite suas respectivas hipóteses nulas.

Para estudar os resultados obtidos na aplicação destes testes, optou-se por duas formas de exposição destes resultados. A princípio, com posse do $p$-valor de cada teste, calculou-se a proporção de vezes que a hipótese nula foi rejeitada (taxa de rejeição) ao nível de significância de 5\%; esta proporção foi contabilizada com base no número de testes executados para cada cenário. Dessa forma, de acordo com sua definição, pode-se considerar que quanto menor for a taxa de rejeição maiores são as evidências de que as suposições não são violadas.

Também tem-se a possibilidade de visualizar estes resultados através de gráficos de dispersão dos $p$-valores obtidos para cada cenário nas bases BA e BP. Quanto maiores forem os $p$-valores resultantes mais indícios existem de que as suposições consideradas são respeitadas, fato este facilmente visualizado em gráficos de dispersão.

A suposição 2, que diz respeito a normalidade, foi investigada por meio do teste de Shapiro-Wilk. Em cada réplica e para cada cenário o teste foi aplicado para os valores preditos das bases BA e BP. A quem desejar informações sobre este teste de hipóteses indica-se, por exemplo, a leitura de Shapiro e Wilk (1965).

Da mesma forma, averiguou-se a suposição 3, de média zero, através do teste de médias para dados normalmente distribuídos com variância conhecida; maiores detalhes podem ser encontrados, por exemplo, em Ross (2009), Magalhães e Lima (2000), e Bussab e Morettin (2013).

Contudo, o processo foi ligeiramente diferente para a verificação da suposição 4 de homocesdasticidade: através do teste de Bartlett, foi analisado se em cada réplica, os valores preditos para a BA apresentaram mesma variância dos valores preditos para a BP. Através deste procedimento tem-se o intuito de verificar se as predições dos interceptos aleatórios de novos grupos possuem dispersão igual a observada nos grupos da base de ajuste. Explicações a respeito do teste de homogeneidade de Bartlett podem ser encontradas, por exemplo, em Bartlett (1937) e Snedecor e Cochran (1989). 


\subsubsection{Objetivos das simulações do MPE para $\mu_{i j}$}

O desempenho do MPE para a média foi analisado através das medidas de desempenho apresentadas anteriormente e de acordo com os procedimentos esclarecidos na seção 2.6.

Anexado a estas análises, deseja-se verificar se o MPE apresenta tendências; isto ocorre se ao observar o gráfico boxplot dos erros puros, estes apresentarem distribuição assimétrica em torno do valor zero. Também se tem interesse em analisar se a distribuição destes erros são semelhantes para as bases de ajuste e de predição de cada cenário de simulação; com isso, espera-se que a metodologia seja tão eficiente para predizer valores que não foram considerados no ajuste do modelo assim como o é para valores que contribuíram para a estimação dos parâmetros do modelo de regressão.

\subsection{Descrição do Estudo}

Com o intuito de analisar a qualidade de predição do MPE proposto no capítulo 3, foram efetuados os estudos presentes neste capítulo. A seguir são listadas e explicadas as premissas e notações consideradas ao longo de todo o estudo.

- construiu-se um banco de dados para que o método fosse aplicado e sua performance avaliada. Este banco de dados é composto por observações de uma variável resposta (Y) e por observações de uma variável explicativa $(\mathrm{X})$, cujo interesse dos pesquisadores é tomar conhecimento de como ela interfere no comportamento da variável resposta;

- a classe de modelos ajustada para Y são os modelos beta mistos definido em (2.5) para $p=1$, o qual é dado por:

$$
g\left(\mu_{i j}\right)=\beta_{0}+\beta_{1} x_{i j}+\alpha_{i} .
$$

Neste caso, as mesmas notações e suposições utilizadas nos outros capítulos prevalecem;

- admita que X tem distribuição uniforme no intervalo $(0,1)$, conforme observa-se nas simulações de Park e Wu (2006), Guoyou e Zhongyi (2008) e Fu e Wang (2012);

- considere também que a função de ligação $g($.$) é a logito, definida como:$

$$
g\left(\mu_{i j}\right)=\log \left(\frac{\mu_{i j}}{1-\mu_{i j}}\right)
$$

- as estimativas dos parâmetros dos modelos foram calculadas através do pacote gamlss;

- as situações em estudo se diferenciam pelos valores dos parâmetros necessários para gerar o banco de dados. Assim sendo, cada uma destas situações é referenciada como um cenário específico;

- os parâmetros que sofrem variação e definem os cenários são:

1. $q$ = número de grupos que compõem o banco de dados; 
2. $p=$ proporção dos grupos que compõem a BA;

3. $\gamma=$ desvio padrão do intercepto aleatório $\alpha_{i}$, para $i=1,2, \ldots q$.

- o número de réplicas para cada cenário é igual a 5000;

- cada grupo é composto por 5 elementos, ou seja, $n_{i}=5$ para todo $i=1,2, \ldots q$;

- os valores definidos para $\beta_{0}, \beta_{1}$ e $\phi$ são respectivamente 0,$5 ; 1$ e 3 ;

- o número de pontos considerados na quadratrura de Gauss-Hermite foi igual a 8;

- por fim, apresenta-se na tabela 4.1 os cenários em estudo.

\begin{tabular}{c|c|c|c}
\hline Cenário & Número de grupos $(q)$ & Proporção dos grupos considerados na BA $(p)$ & $\gamma$ \\
\hline 1 & 10 & 0,7 & 1 \\
2 & 10 & 0,7 & 1,5 \\
3 & 20 & 0,7 & 1 \\
4 & 10 & 0,9 & 1 \\
\hline
\end{tabular}

Tabela 4.1: Cenários das simulações.

Nota-se que as bases totais, junção das bases de predição e de ajuste, são de tamanho moderado: elas variam de 50 a 100 observações. Veja também que a base de predição é composta por um número de elementos que varia, de acordo com os cenários, entre 5 e 30.

\subsubsection{Algoritmo de implementação}

O algoritmo implementado para atingir os objetivos deste capítulo se baseia nos passos adiante.

1. Definir valores para $q, p$ e $\gamma$;

2. Gerar valores da variável independente a partir da distribuição uniforme no intervalo $(0,1)$; Início das Réplicas.

3. Gerar valores do intercepto aleatório a partir da distribuição normal com média 0 e desviopadrão $\gamma$;

4. Calcular os valores de $\mu_{i j}$ de acordo com o modelo (2.5) em estudo;

5. Gerar valores da variável resposta a partir da distribuição beta com parâmetros $\mu_{i j}$ e $\phi$;

6. Ajustar o modelo apenas com efeitos fixos (2.4) para a BA;

7. Ajustar o modelo com intercepto aleatório (2.5) para a BA;

8. Calcular o MPE dos interceptos aleatórios (conforme a expressão 3.10) e de $\mu_{i j}$ (conforme a expressão 3.13) para as bases BA e BP;

Fim das Réplicas.

9. Calcular medidas de desempenho;

10. Aplicar testes de hipóteses. 


\subsection{Análise dos resultados}

Antes de começar a explorar a performance do MPE, será efetuada uma breve averiguação das estimativas para os parâmetros $\beta_{0}, \beta_{1}$ e $\phi$ obtidas nas simulações. Optou-se por isto já que se sabe que o comportamento destas estimações pode influenciar no desempenho do MPE. As medidas consideradas nesta investigação foram a média das estimativas, a REQM e o viés relativo médio das estimativas. Seus resultados para os parâmetros $\beta_{0}, \beta_{1}$ e $\phi$ se encontram, respectivamente, nas tabelas $4.2,4.3$ e 4.4 .

\begin{tabular}{c|c|c|c}
\hline Cenário & Média das estimativas & REQM das estimativas & Viés relativo médio das estimativas \\
\hline 1 & 0,4607 & 0,7251 & $-0,0785$ \\
2 & 0,4211 & 0,8156 & $-0,1577$ \\
3 & 0,4821 & 0,5358 & $-0,0358$ \\
4 & 0,4747 & 0,6598 & $-0,0506$ \\
\hline
\end{tabular}

Tabela 4.2: Medidas de desempenho da estimação de $\beta_{0}$ pelo modelo beta misto $\left(\beta_{0}=0,5\right)$.

\begin{tabular}{c|c|c|c}
\hline Cenário & Média das estimativas & REQM das estimativas & Viés relativo médio das estimativas \\
\hline 1 & 1,124 & 0,9877 & 0,1237 \\
2 & 1,044 & 0,9310 & 0,0443 \\
3 & 1,105 & 0,7876 & 0,1051 \\
4 & 1,131 & 0,9485 & 0,1313 \\
\hline
\end{tabular}

Tabela 4.3: Medidas de desempenho da estimação de $\beta_{1}$ pelo modelo beta misto $\left(\beta_{1}=1\right)$.

\begin{tabular}{c|c|c|c}
\hline Cenário & Média das estimativas & REQM das estimativas & Viés relativo médio das estimativas \\
\hline 1 & 5,546 & 4,4152 & 0,8485 \\
2 & 5,692 & 4,5022 & 0,8973 \\
3 & 5,631 & 4,4868 & 0,8770 \\
4 & 5,667 & 4,4779 & 0,8889 \\
\hline
\end{tabular}

Tabela 4.4: Medidas de desempenho da estimação de $\phi$ pelo modelo beta misto $(\phi=3)$.

Comparando os resultados entre os cenários, nota-se que a medida que mais varia dentre eles é o viés relativo médio; isto ocorre para os parâmetros $\beta_{0}$ e $\beta_{1}$.

Convém ressaltar também que, apesar de $\beta_{0}$ apresentar ligeira subestimação e $\beta_{1}$ ser fracamente superestimado, para $\beta_{0}$ e $\beta_{1}$ a média das estimativas ao longo das réplicas foi próxima dos seus valores verdadeiros.

Porém, quando se observa o valor da média das estimativas de $\phi$, nota-se que os valores estão distantes do valor verdadeiro $(\phi=3)$; adicionalmente observa-se que, para a situação em estudo, a magnitude da REQM e do viés relativo médio destas estimativas de $\phi$ são valores altos. 


\subsubsection{Resultados das simulações do MPE do intercepto aleatório}

Na tabela 4.5 encontram-se os valores das taxas de rejeição dos testes de Shapiro-Wilk aplicados nos estudos de simulação, calculadas conforme explicado na subseção 4.1.1. A análise destas informações, juntamente com a interpretação dos $p$-valores obtidos neste mesmo contexto, possibilita avaliar a suposição de normalidade dos valores preditos dos efeitos aleatórios pelo MPE dado na equação (3.10).

Quanto menores forem os valores das taxas de rejeição, menos indícios existem de que a suposição de normalidade não é satisfeita. Porém, a análise das taxas de rejeição é efetuada em conjunto com a interpretação dos p-valores, neste caso dispostos nas figuras 4.1 e 4.2. Deseja-se observar, nestes estudos, $p$-valores altos para os testes de Shapiro-Wilk aplicados, pois dessa forma, as evidências de rejeição da hipótese nula são pequenas e assim os valores preditos apresentam distribuição normal.

\begin{tabular}{c|c|c}
\hline Cenário & Taxa de rejeição para a BA & Taxa de rejeição para a BP \\
\hline 1 & 0,0380 & 0,0084 \\
2 & 0,0598 & 0,0204 \\
3 & 0,2128 & 0,0658 \\
4 & 0,1142 & 0,0928 \\
\hline
\end{tabular}

Tabela 4.5: Taxa de rejeição do teste de Shapiro-Wilk para os valores preditos do intercepto aleatório.
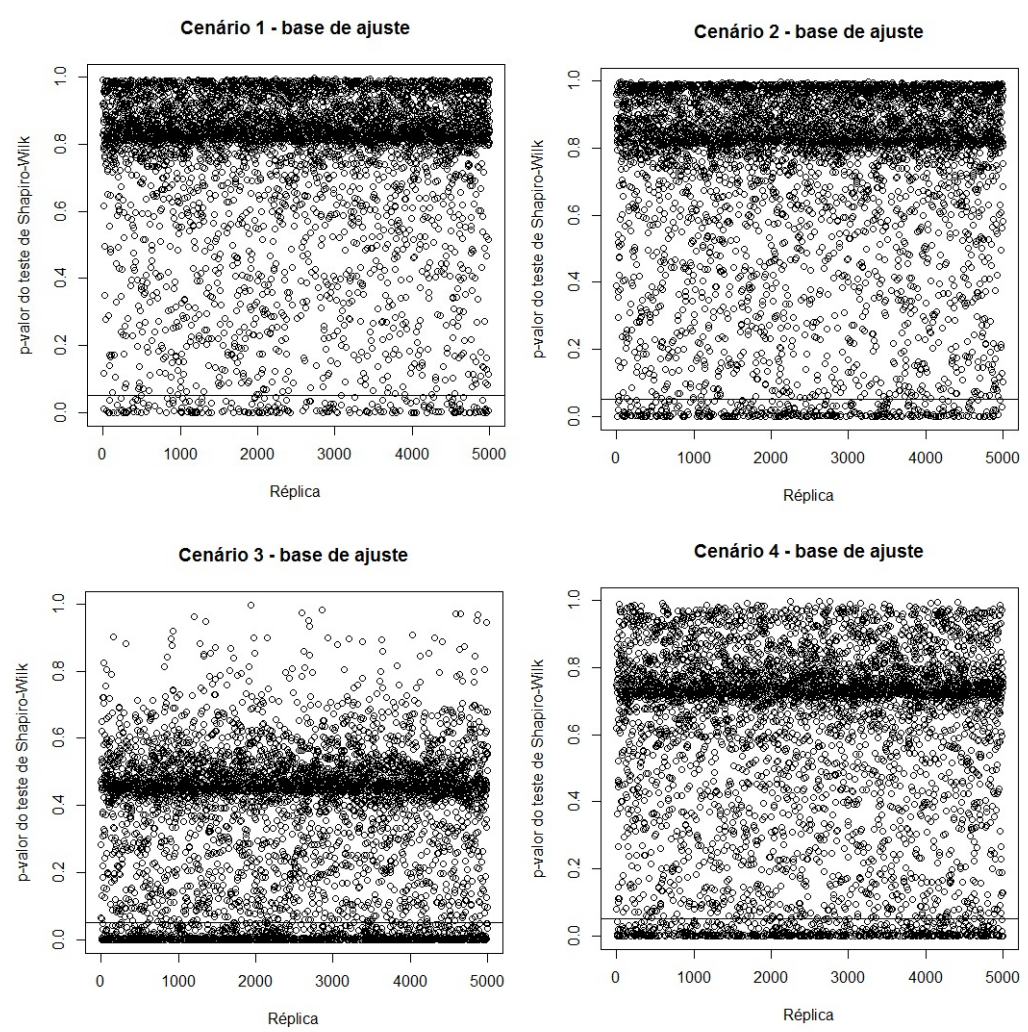

Figura 4.1: p-valor do teste de Shapiro-Wilk para os valores preditos do intercepto aleatório na base de ajuste. 
Observe que, as bases de ajuste dos cenários 1, 2 e 4 apresentaram resultados satisfatórios para a taxa de rejeição e também para os $p$-valores considerados para seu cálculo; ou seja, para estes casos, os resultados indicam que a suposição de normalidade é satisfeita pelo preditor em estudo. Contudo, os valores preditos para a BA do cenário 3 apresentaram uma taxa de rejeição do teste de Shapiro-Wilk demasiadamente superior a 0,05 .

Para averiguar mais detalhadamente a suposição de normalidade na BA do cenário 3 , é interessante analisar a figura 4.1. Nesta figura pode-se vizualizar que os $p$-valores resultantes da aplicação do teste para este cenário e base se concentram em uma nuvem de pontos em torno do valor 0,45. Este fato é considerado bom, pois isto indica que a maioria das réplicas da BA do cenário 3 não apresentaram evidências de violação da suposição de normalidade.

Sabe-se que a distribuição de probabilidade normal é caracterizada, dentre outros aspectos, por possuir coeficiente de assimetria igual a zero e coeficiente de curtose igual a 3. Comparando estes valores com os obtidos para os valores preditos da BA do cenário 3 (disponíveis na tabela 4.7), respectivamente iguais a -0,375 e 2,919, nota-se que eles são semelhantes e, com isso não apresentam indícios de que a suposição de normalidade é violada.
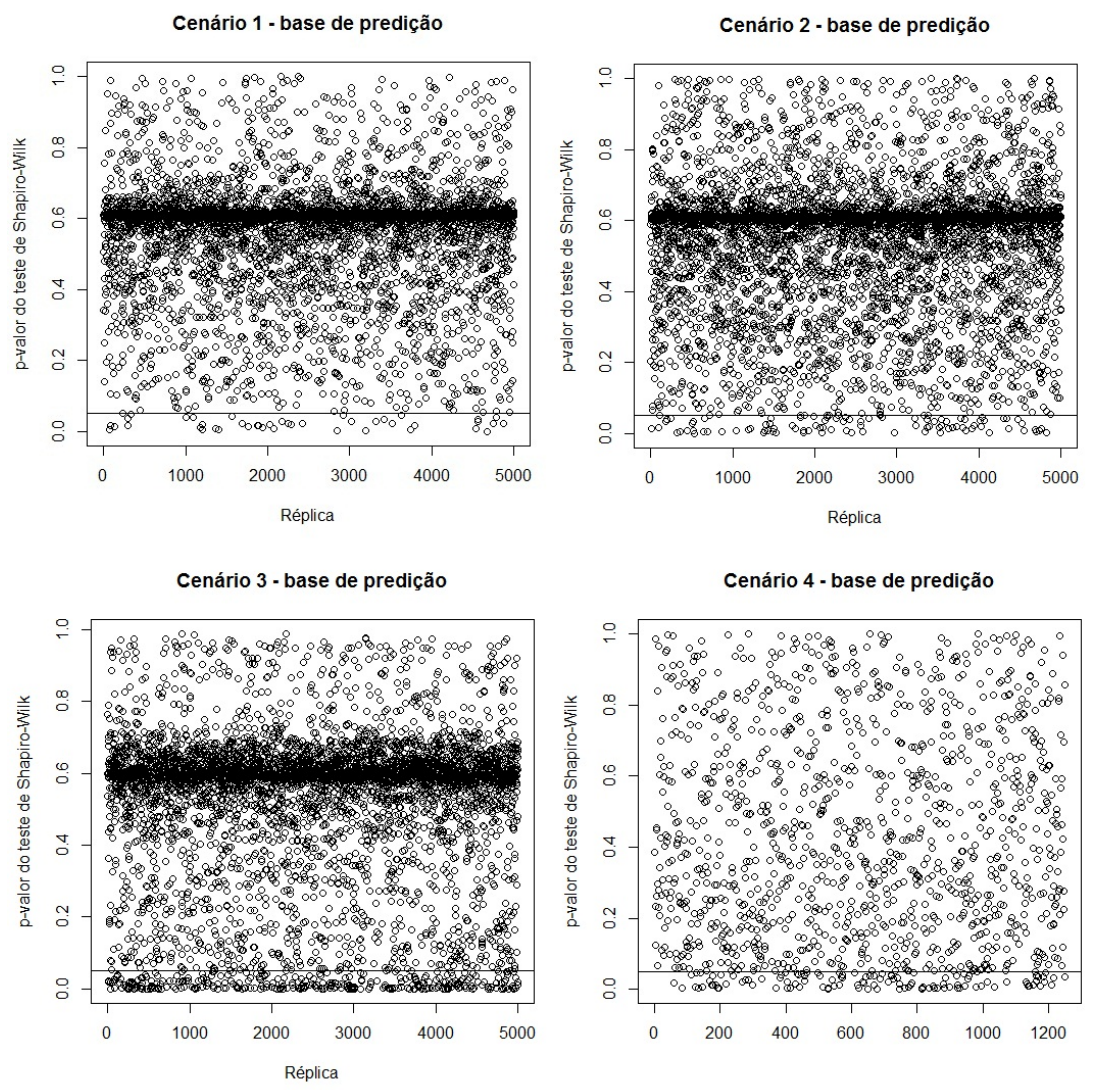

Figura 4.2: p-valor do teste de Shapiro-Wilk para os valores preditos do intercepto aleatório na base de predição.

Quando se analisa estas mesmas taxas de rejeição e $p$-valores para as bases de predição dos quatro cenários em estudo tem-se que: estes resultados indicam que os valores preditos dos efeitos aleatórios dos cenários 1, 2 e 3 podem ser considerados normalmente distribuídos e; com relação ao cenário 4, apesar de sua taxa de rejeição não ser tão pequena quanto às observadas para os outros 
cenários desta mesma base (isto pode ser devido ao fato de ser uma base de predição de tamanho menor), os seus respectivos $p$-valores sugerem que não existem fortes evidências para não considerar estas predições como sendo normalmente distribuídas.

Com relação ao teste de médias, cuja hipótese nula diz que a média em teste é igual a zero, obteve-se os resultados expostos na tabela 4.6 e nas figuras 4.3 e 4.4. Estes resultados são analisados da mesma forma como efetuada para o teste de Shapiro-Wilk.

\begin{tabular}{c|c|c}
\hline Cenário & Taxa de rejeição para a BA & Taxa de rejeição para a BP \\
\hline 1 & 0,0920 & 0,0082 \\
2 & 0,0514 & 0,0040 \\
3 & 0,2798 & 0,0564 \\
4 & 0,1546 & 0,0008 \\
\hline
\end{tabular}

Tabela 4.6: Taxa de rejeição do teste de médias para os valores preditos do intercepto aleatório.
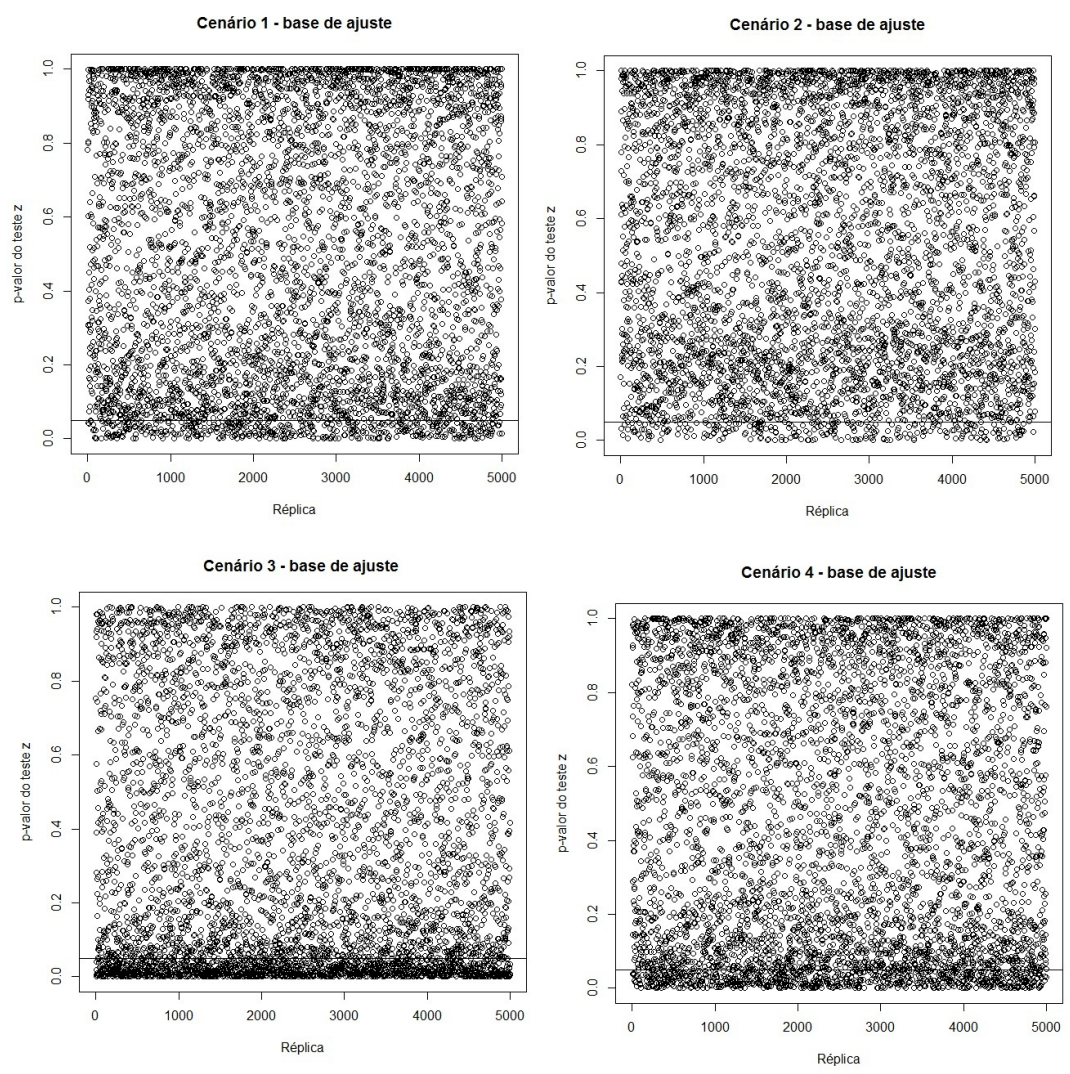

Figura 4.3: p-valor do teste de médias para os valores preditos do intercepto aleatório na base de ajuste. 

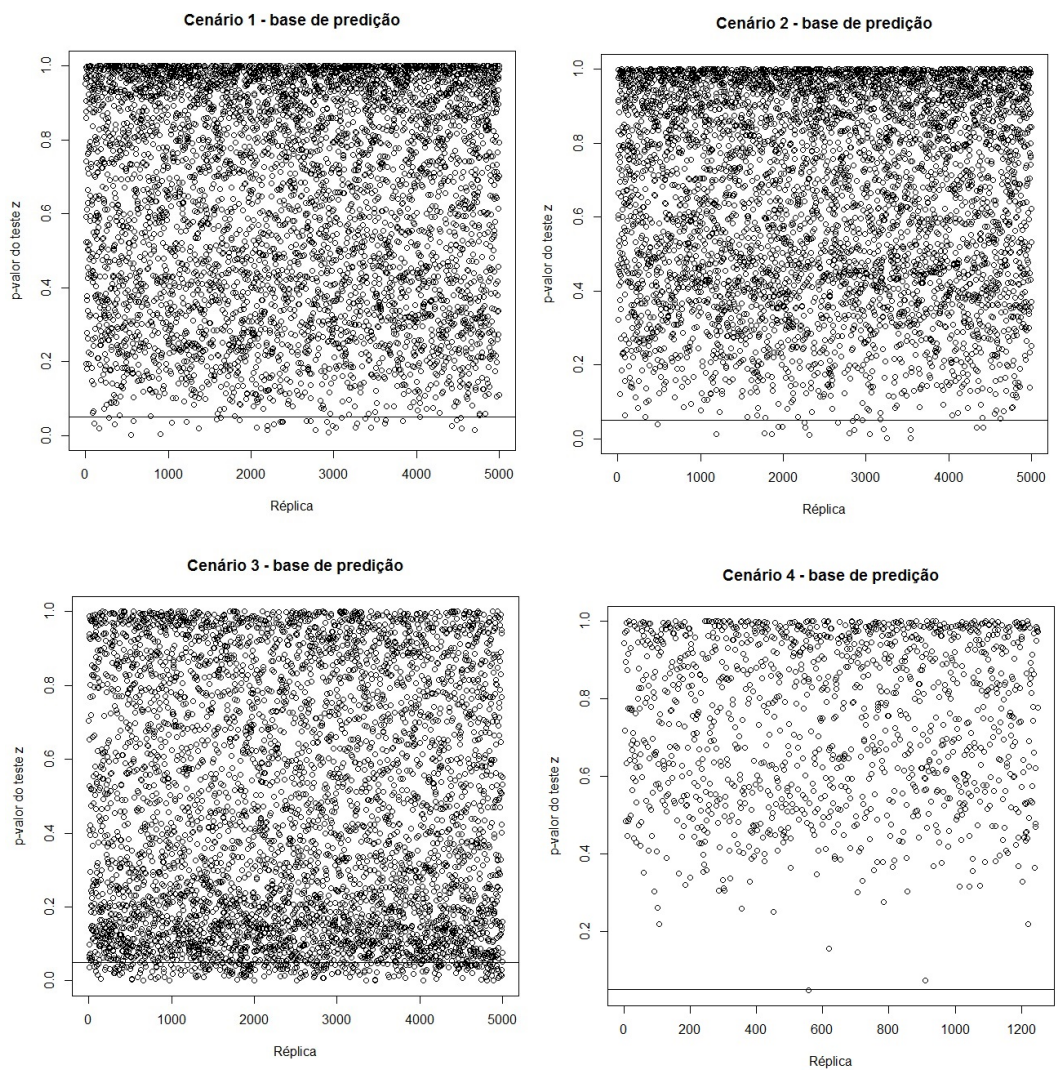

Figura 4.4: p-valor do teste de médias para os valores preditos do intercepto aleatório na base de predição.

Da mesma forma como ocorrido com o teste de Shapiro-Wilk, com exceção da BA do cenário 3, os resultados indicam que não se pode rejeitar que a média dos valores preditos seja igual a zero, pois os $p$-valores são razoavelmente altos e as taxas de rejeição não se distanciam de forma excessiva do nível de significância considerado.

Porém, para a base de ajuste do cenário 3, a taxa de rejeição foi consideravelmente maior que 0,05 (assim como observado no teste de Shapiro-Wilk) e o gráfico de dispersão dos $p$-valores do teste de médias para a BA do cenário 3 concentra os valores abaixo de $10 \%$.

Dadas as evidências de rejeição da hipótese nula que a média das predições do intercepto aleatório é igual a zero na base de ajuste do cenário 3, calculou-se as estatísticas descritivas destes valores preditos e elas encontram-se na tabela 4.7; estas medidas intensificam a ideia de que os dados não aparentam apresentar média igual a zero. Este fato pode sugerir que ao trabalhar com um número de grupos grande, a suposição 3 pode não permanecer sendo válida. 


\begin{tabular}{c|c}
\hline Estatística & Valor da estatística \\
\hline Mínimo & $-2,861$ \\
Primeiro quartil & $-0,700$ \\
Mediana & $-0,354$ \\
Média & $-0,406$ \\
Terceiro quartil & $-0,066$ \\
Máximo & 1,744 \\
Curtose & 2,919 \\
Assimetria & $-0,375$ \\
\hline
\end{tabular}

Tabela 4.7: Estatísticas descritivas dos valores preditos do intercepto aleatório para a BA do cenário 3.

O teste de Bartlett para checar as hipóteses de homogeneidade dos valores preditos apresentou bons resultados pois, as taxas de rejeição contabilizadas (vide tabela 4.8) sugerem que não há indícios para rejeitar a hipótese de homogeneidade testada, já que são menores que $5 \%$ para os cenários 1 e 4 e não se distanciam exageradamente do valor 0,05 nos cenários 2 e 3 .

\begin{tabular}{c|c}
\hline Cenário & Taxa de rejeição \\
\hline 1 & 0,0468 \\
2 & 0,1112 \\
3 & 0,0674 \\
4 & 0,0016 \\
\hline
\end{tabular}

Tabela 4.8: Taxa de rejeição do teste de Bartlett entre os valores preditos do intercepto aleatório das bases de ajuste e de predição.
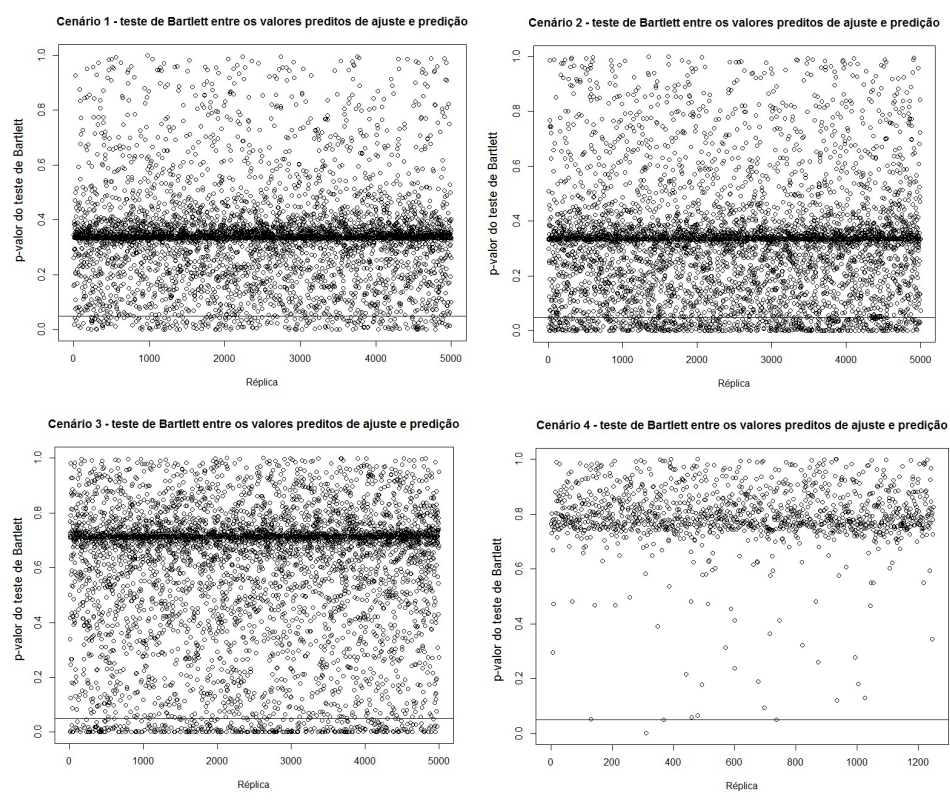

Figura 4.5: p-valor do teste de Bartlett para os valores preditos do intercepto aleatório . 
Importante verificar na figura 4.5 que os $p$-valores do teste de Bartlett se concentram em nuvens de pontos distantes e superiores ao nível de significância de 5\%, o que é um ótimo resultado pois indica que não há indícios para rejeitar a hipótese nula de que as predições de ambas as bases de dados (BA e BP) possuem variâncias iguais.

Com isso, conclui-se que a suposição 4 é válida para os interceptos aleatórios preditos dos grupos do banco de dados simulado.

Assim, através das análises efetuadas neste estudo, pode-se verificar que o desempenho do melhor preditor de Bayes empírico para o intercepto aleatório para a base de predição é muito semelhante ao do aplicado na base de ajuste; garantindo mais confiabilidade nas tomadas de decisões que se baseiam nestes casos e, que os valores preditos por meio do MPE permanecem satisfazendo as suposições referentes ao intercepto aleatório do modelo, com a ressalva de que ao se trabalhar com um número mais elevado de grupos com tamanho pequeno $(n=5)$, a média dos efeitos aleatórios preditos pode não ser igual a zero.

\subsubsection{Resultados das simulações do MPE de $\mu_{i j}$}

Adiante encontram-se os resultados dos estudos desenvolvidos para o caso específico do MPE da média e suas respectivas interpretações.

Os valores expostos na tabela 4.9 indicam que a relação de $q$ e de $p$ com a REQMP é levemente decrescente na base de predição; ou seja, o aumento no número de grupos ocasiona a diminuição da REQMP, assim como ocorre com a proporção da base de dados considerada para estimação dos parâmetros do modelo de regressão.

Observa-se, comparando a REQMP entre os cenários 1 e 2 na tabela 4.9, que seu valor nas simulações aumentou quando o valor do desvio-padrão do intercepto aleatório passou de 1 para 1,5 em ambas as bases. Por outro lado, na base de ajuste, quando o tamanho de grupos aumenta (cenário 1 em relação ao cenário 3) a REQMP permaneceu similar. O mesmo aconteceu quando a proporção de grupos considerados na base de ajuste (BA) aumentou (cenário 1 em relação ao cenário 4).

\begin{tabular}{c|c|c}
\hline Cenário & REQMP para a BA & REQMP para a BP \\
\hline 1 & 0,1979 & 0,2189 \\
2 & 0,2567 & 0,2834 \\
3 & 0,1983 & 0,2077 \\
4 & 0,1987 & 0,2137 \\
\hline
\end{tabular}

Tabela 4.9: REQMP do MPE de $\mu_{i j}$ para os dados da BA e da BP.

Os valores de REQMP das bases de ajuste e de predição em todos os cenários são próximos. A diferença entre estes valores se mostrou maior para o cenário 2, mas os resultados demonstram que, no quesito REQMP, a performance do MPE é semelhante para ambas as bases de dados. 
A averiguação de existência de tendenciosidade no MPE, efetuada através dos gráficos boxplot dos erros puros das predições, indicou bons resultados. Os gráficos resultantes das simulações, disponibilizados na figura 4.6, sugerem que a predição efetuada pelo MPE é não tendenciosa para ambos os casos considerados: quando se aplica a metodologia para os dados que foram e que não foram utilizados para o ajuste do modelo.
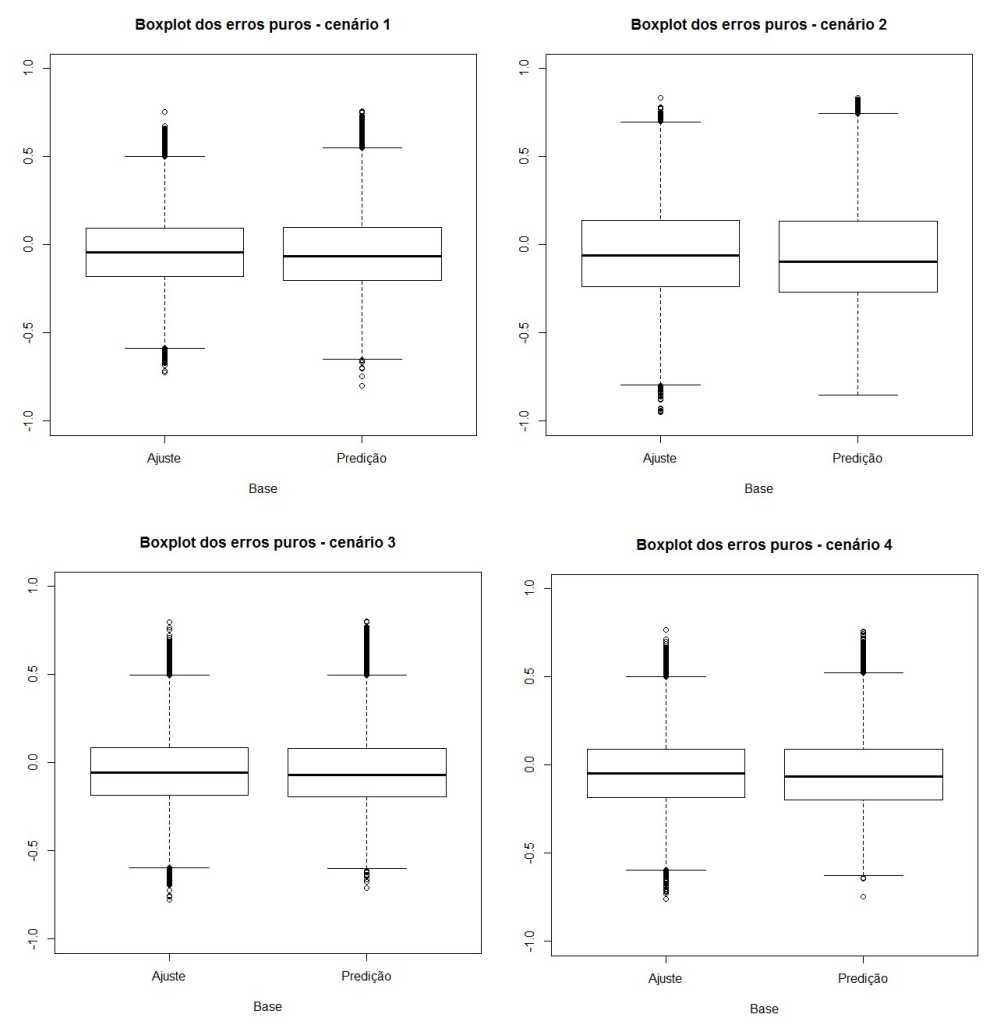

Figura 4.6: Boxplot dos erros puros de predição para as bases de ajuste e de predição.

Novamente observa-se que os resultados foram muito similares para a BA e BP, pois a distribuição dos erros puros são muito semelhantes para ambas as bases.

A figura 4.7 contém os gráficos do tipo QQ-plot dos resíduos quantílicos aleatorizados definidos na subseção 2.6.3. Estes gráficos revelam que o MPE teve desempenho adequado, de forma geral, para o propósito em questão. Também observa-se que os QQ-plots dos resíduos da base de predição parecem apresentar um leve afastamento da suposição de normalidade.

Analisando mais especificamente os cenários, observa-se que o cenário 4 apresentou para a BP valores mais distantes da reta nas suas extremidades, porém não há indícios de que a suposição de normalidade é violada. Assim sendo, os resultados foram satisfatórios com relação à análise da bondade de ajuste dos modelos e também da predição do MPE através dos resíduos quantílicos aleatorizados. 

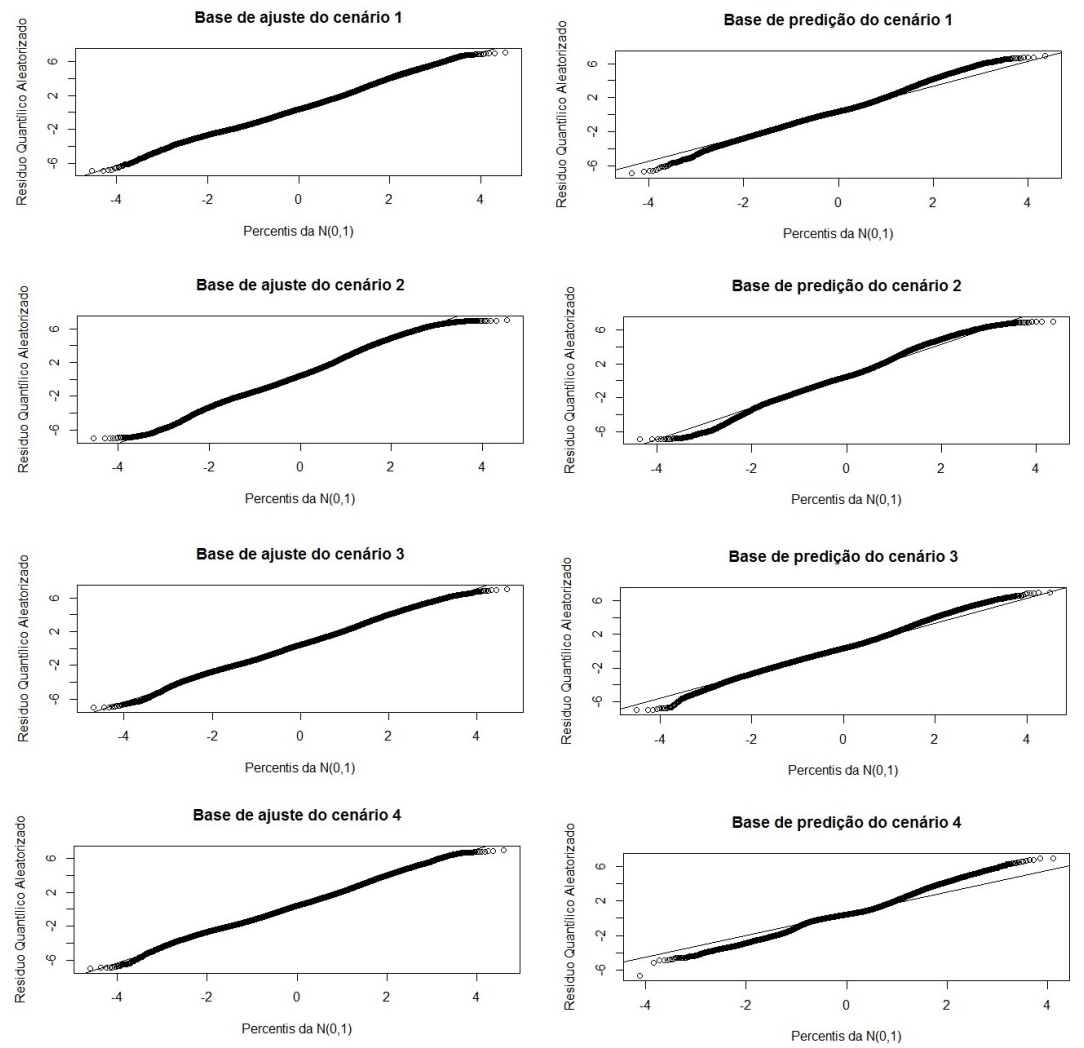

Figura 4.7: QQ-plot dos resíduos quantilicos aleatorizados para as bases de ajuste e de predição.

\begin{tabular}{c|c|c}
\hline Cenário & Viés relativo médio para a BA & Viés relativo médio para a BP \\
\hline 1 & 0,0512 & 0,0640 \\
2 & 0,2794 & 0,3429 \\
3 & 0,0542 & 0,0482 \\
4 & 0,0524 & 0,0558 \\
\hline
\end{tabular}

Tabela 4.10: Viés relativo médio do $M P E$ de $\mu_{i j}$ para os dados da BA e da BP.

O último ítem analisado para o MPE de $\mu_{i j}$ foi o viés relativo médio, cujos valores encontram-se na tabela 4.10. Assim como assinalado para a REQMP, a relação entre o desvio dos efeitos aleatórios $(\gamma)$ e o viés relativo médio é crescente, ou seja, a medida que o valor de $\gamma$ aumenta o valor do viés relativo médio também cresce.

Na BA esta medida parece ser similar nos cenários 1, 3 e 4, entretanto, na BP o viés relativo diminui quando o número de grupos aumenta (cenário 3) e também quando o valor de $p$ aumenta (cenário 4), como já era esperado. Este fato não foi observado com tanta evidência ao se comparar os valores da REQMP.

Assim sendo, por meio dos resultados dos estudos de simulação aqui apresentados, pode-se concluir que:

- as predições do melhor preditor empírico para o intercepto aleatório satisfazem as mesmas suposições admitidas no modelo em estudo: normalidade, homogeneidade da variância e média 
igual a zero; sendo que esta última pode não ser respeitada quando o número de grupos for elevado e o tamanho dos grupos for pequeno;

- o MPE para a média não apresenta tendências, mas apresenta aumento da REQMP e do viés relativo médio à medida que a variância do efeito aleatório aumenta e;

- o melhor preditor empírico de ambos os termos em questão tiveram desempenho muito semelhantes para as bases de ajuste e de predição.

Em definitiva, pode-se afirmar que o desempenho do MPE para o intercepto aleatório e para a média são satisfatórios. 


\section{Capítulo 5}

\section{Aplicações}

Este capítulo tem por objetivo ilustrar o método de predição desenvolvido nesta dissertação. O seu conteúdo é importante, pois explora as diversas facetas de utilização da ferramenta em estudo e auxilia o leitor na compreensão do tema.

Assim, optou-se por apresentar duas aplicações, exemplificando todas as alternativas que englobam o MPE. Ambas as aplicações se referam a dados de saúde; decidiu-se por esta área pois a utilização de modelos preditivos por ela tem crescido de forma relevante, e pela grande contribuição que estes modelos podem proporcionar à avaliação do sucesso dos tratamentos, assim como escreve Papoila (2012).

Inicialmente o MPE vai ser ferramenta de análise de um banco de dados de recém-nascidos, aonde se tem interesse em explorar a forma como características clínicas e fatores socioeconômicos das gestantes e ocorrências na gravidez podem influenciar no peso do bebê ao nascer. Todo o processo de análise exploratória, ajuste de modelos e predição está descrito com o intuito de esclarecer os detalhes envolvidos. Adiante o leitor pode verificar que, neste caso, o MPE foi calculado para novos indivíduos de grupos já existentes, em função da estrutura dos dados e do modelo ajustado.

A segunda pesquisa consiste num estudo longitudinal na área de odontologia, no qual se realizou o acompanhamento de pacientes com periodontite até 12 meses após efetuado o tratamento. As diversas informações aferidas nestes pacientes são de valia para: entender a eficácia do tratamento, quais são os parâmetros clínicos que reagem a ele e de que forma estas reações acontecem no período estudado. Este caso possibilita exemplificar a predição para novos grupos; veja que trata-se de dados longitudinais de pacientes e que as medidas de cada paciente compõem um grupo.

Em ambos os bancos de dados, os resultados observados foram satisfatórios, ressaltando o benefício de utilizar-se das ferramentas adequadas de análise.

\subsection{Dados de peso de recém-nascidos}

A gestação é um momento marcante na vida das mulheres e neste período elas se deparam com diversas alterações fisiológicas e metabólicas. Visando sempre preservar a saúde das gestantes e do bebê que está sendo gerado, é de grande relevância para os profissionais da saúde ter conhecimento sobre a forma como o ganho de peso das grávidas e outros fatos ocorridos na gestação podem influenciar no peso do recém-nascido.

Em estudos como McDermott et al. (2000) e Drehmer (2010) aborda-se a influência de irregularidades na composição do peso corpóreo das gestantes em complicações na saúde dos recém- 
nascidos, como peso inadequado, problemas relacionados ao parto, entre outros. Em posse destas informações, políticas de prevenção destas complicações podem ser melhor delineadas.

O estudo foi desenvolvido no Hospital Amparo Maternal e nele foram acompanhadas 260 gestantes entre março de 1997 e março de 1998. Além das informações de peso e de seus respectivos componentes (massa de gordura, água corporal total e massa livre de gordura), foram aferidos dados como escolaridade, estado civil, informações socioeconômicas, histórico de gestações anteriores, hábitos de tabagismo, dentre outros.

Ao final do estudo tomou-se conhecimento das condições de nascimento dos bebês de apenas 130 das 260 gestantes iniciais. Este banco de dados já foi explorado por Silva e Giampaoli (2013) em diversas perspectivas estatísticas e nesta seção tem-se interesse em explorar os dados por meio dos modelos de regressão beta com intercepto aleatório.

\subsubsection{Análises}

A natureza da variável peso do bebê ao nascer é assumir valores positivos e, restritos por um limite superior que pode ser aproximado pelo máximo valor observado na amostra. Dessa forma, para efetuar a análise exploratória dos dados e, com isso, analisar qual classe de modelos é adequada para ajustá-los, a variável em questão passou pela padronização (transformação) dada pela equação (5.1).

$$
z_{i j}=\frac{\left(y_{i j}-a\right)}{(b-a)}
$$

,em que:

- $y_{i j}$ é o valor observado da variável original;

- $z_{i j}$ é o valor observado da variável padronizada;

- $a$ é o valor mínimo, observado na amostra, da variável original e;

- $b$ é o valor máximo, observado na amostra, da variável original.

Este procedimento de padronização mantém, proporcionalmente, as mesmas distâncias entre os valores observados na amostra, de forma que não há perda de informações e, através dele a variável padronizada assume valores no intervalo $(0,1)$. Assim sendo, daqui em diante, ao ser mencionada a variável peso do bebê ao nascer entenda-se como sendo a forma padronizada da mesma.

Adiante são descritas as variáveis exploradas neste estudo.

1. pesorn: peso do bebê ao nascer (em gramas);

2. taxapeso: taxa de ganho de peso na gravidez ( $\mathrm{Kg} /$ semana);

3. taxamagra: taxa de ganho de massa magra na gravidez ( $\mathrm{Kg} /$ semana);

4. taxagorda: taxa de ganho de massa gordurosa na gravidez ( $\mathrm{Kg} /$ semana);

5. taxaagua: taxa de ganho de água na gravidez (litros/semana); 
6. igrn: idade gestacional do bebê ao nascer (em semanas);

7. idade: idade da gestante (em anos);

8. escolaridade: tempo de estudo da gestante (em anos);

9. paridade: esta variável assume valor 1 quando for a primeira gestação da grávida e 0 caso contrário;

10. aborto: esta variável assume valor 1 caso a gestante já tenha abortado anteriormente e 0 caso contrário;

11. oms: classificação do estado nutricional da gestante no início da gravidez de acordo com a OMS (organização mundial da saúde); as gestantes podem ser classificadas como desnutridas, eutróficas (peso adequado), com sobrepeso e obesas;

12. has: esta variável assume valor 1 se a gestante possuía ou desenvolveu hipertensão e 0 caso contrário;

13. cardio: esta variável assume valor 1 se a gestante possuía ou desenvolveu cardiopatia e 0 caso contrário;

14. fumodic: esta variável assume valor 1 para gestantes fumantes e 0 caso contrário;

15. infeccao: indica a situação da gestante em relação ao desenvolvimento de infecção urinária na gestação: não desenvolveu, desenvolveu e tratou e desenvolveu e não tratou;

16. sexorn: esta variável assume valor 1 se o recém-nascido é do sexo masculino e 0 caso contrário.

Em pesquisas como esta, além do interesse em tomar conhecimento dos fatores que influenciam na saúde do bebê ao nascer, os profissionais possuem interesse em aproveitar as informações coletadas das pacientes para auxiliar no pré-natal de novas gestantes; para isso, os métodos de predição são de grande valia.

Nesta aplicação optou-se por utilizar $70 \%$ dos dados para a estimação dos parâmetros necessários ao cálculo do MPE e os restantes $30 \%$ foram tratados como novas gestantes. Estes dados serão aqui mencionados, respectivamente, como base de ajuste (BA) e base de predição (BP). 
Histograma do peso dos recém-nascidos na base de ajuste

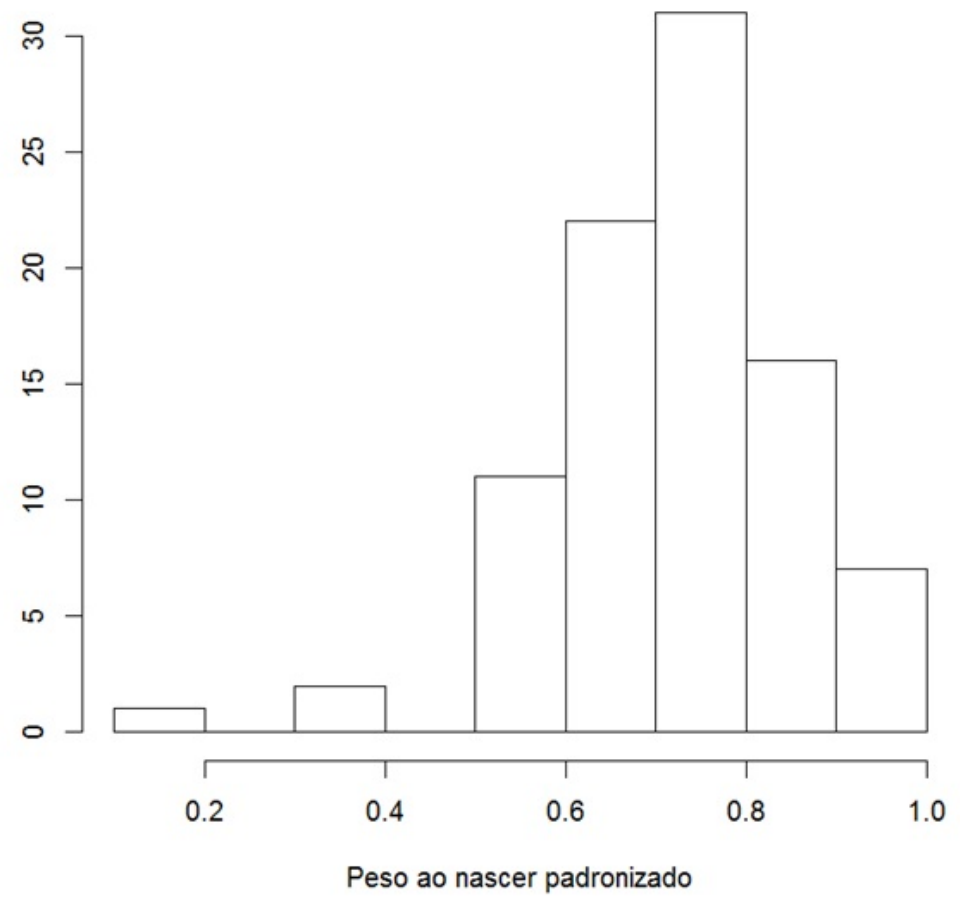

Figura 5.1: Histograma do peso ao nascer dos recém-nascidos da base de ajuste.

Note, pela figura 5.1, que o peso dos recém-nascidos apresenta distribuição assimétrica, concentrando os valores no intervalo $(0,7 ; 0,8)$; esta característica, dentre outras, sugere a utilização da distribuição beta para a análise da variável resposta.

Pesquisas anteriores, como McDermott et al. (2000), evidenciam diferenças nos padrões dos pesos dos recém-nascidos de gestantes que desenvolveram infecção no trato urinário durante a gravidez e de gestantes que não a desenvolveram, sugerindo assim que sejam considerados efeitos aleatórios no modelo beta, em que os grupos são definidos a partir desta variável.

Veja na figura 5.2 como esta diferença ocorre no banco de dados analisado: diferentemente do esperado, na amostra coletada, os bebês de gestantes que não desenvolveram infecção urinária nasceram com menor peso mediano que bebês de gestantes que tiveram infecção urinária; e, dentre estas últimas, as que não passaram por tratamento tiveram bebês com maior peso mediano que as que passaram por tratamento. 


\section{Boxplot do peso dos recém-nascidos na BA segundo a variável infecção}

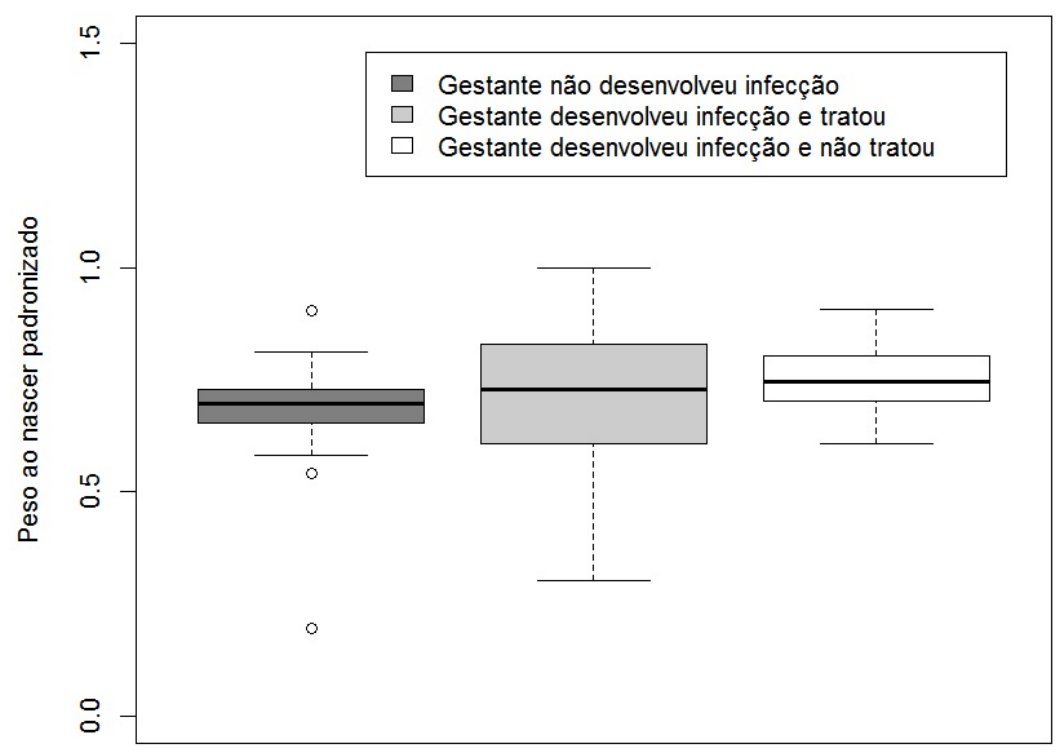

Figura 5.2: Boxplot da variável peso ao nascer dos recém-nascidos da BA segundo a variável infeccao.

Sendo as gestantes classificadas de acordo com a variável infeccao, o banco de dados passa a apresentar três grupos, como ilustrado na figura 5.3.

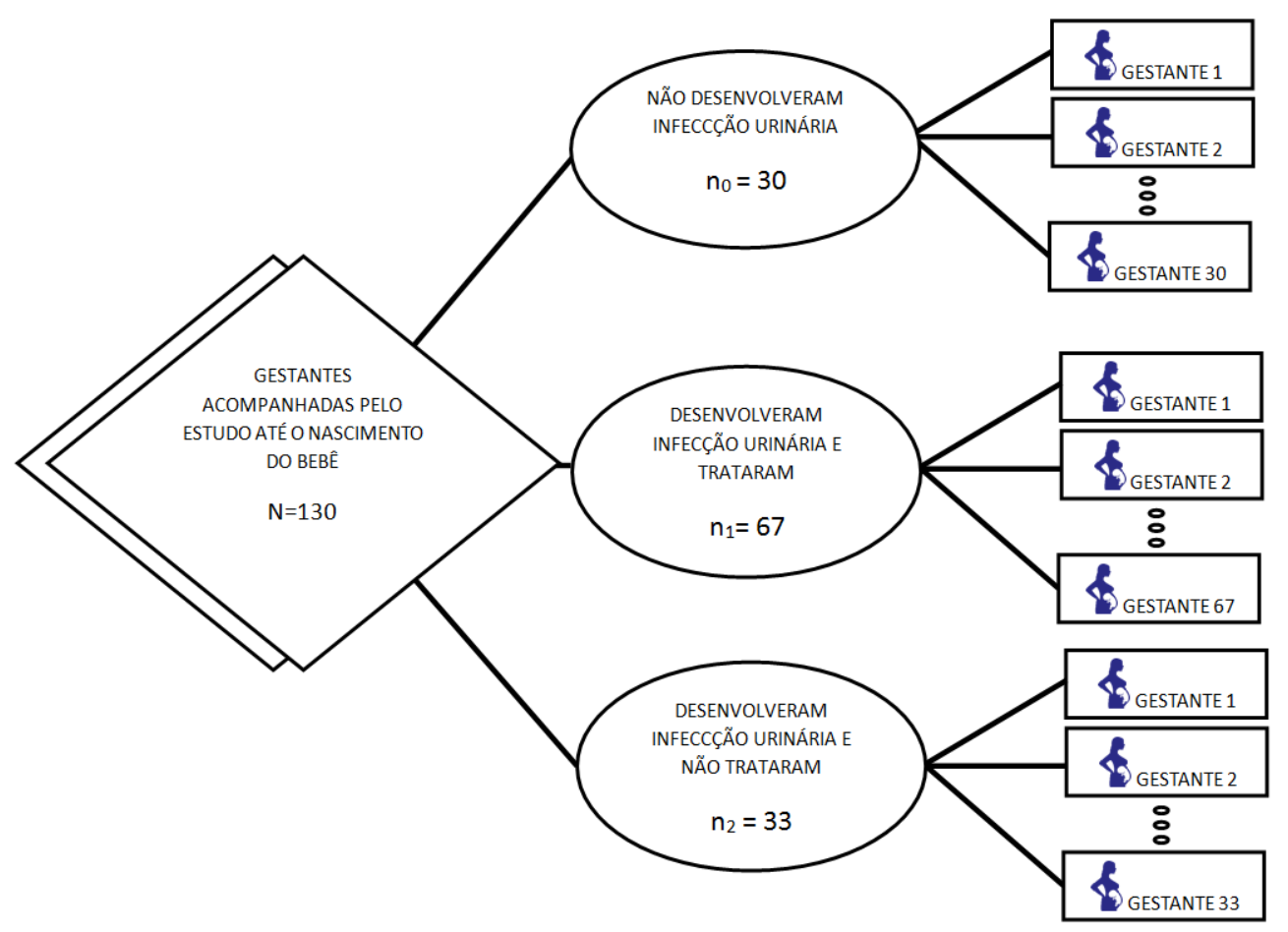

Figura 5.3: Estrutura hierárquica dos dados de gestantes.

O modelo inicial ajustado (2.5) considerou como variáveis explicativas as variáveis $3, \ldots, 16$ ou $2,6, \ldots, 16$ (previamente definidas nesta seção). Foi realizado um processo de seleção de variáveis no modelo e através do critério de informação de Akaike (AIC), das considerações de pesquisadores e de publicações da área, averiguou-se que um modelo misto parcimonioso para a variável resposta é 
o que se apresenta na equação (5.2).

$$
\log \left(\frac{\mu_{i j}}{1-\mu_{i j}}\right)=\beta_{0}+\beta_{1} \text { igrn }_{i j}+\beta_{2} \text { aborto }_{i j}+\beta_{3} \text { sexorn }_{i j}+\beta_{4} \text { taxapeso }_{i j}+\alpha_{i},
$$

onde:

- $j$ referencia o recém-nascido/gestante;

- $i$ indica a qual classificação da variável infeccao o recém-nascido/gestante pertence:

- $i=0$ indica o grupo de gestantes que não desenvolveram infecção urinária na gestação;

- $i=1$ indica o grupo de gestantes que desenvolveram infecção urinária e esta foi tratada;

- $i=2$ indica o grupo de gestantes que desenvolveram infecção urinária e esta não foi tratada.

- $y_{i j}$ é o peso padronizado ao nascer do $j$-ésimo bebê cuja mãe pertence ao $i$-ésimo grupo;

- $\alpha_{i}$ é o intercepto aleatório associado ao $i$-ésimo grupo;

- $\alpha_{0}, \alpha_{1}$ e $\alpha_{2}$ são independentes e identicamente distribuídos $N\left(0, \gamma^{2}\right)$;

- $Y_{i j} \mid \alpha_{i}$ são condicionalmente independentes e possuem distribuição $\operatorname{Beta}\left(\mu_{i j}, \phi\right)$ e;

- $\beta_{0}, \beta_{1}, \beta_{2}, \beta_{3}, \beta_{4}, \gamma$ e $\phi$ são parâmetros do modelo.

A análise de diagnósticos na figura 5.4 revelou a adequação do modelo final ajustado (5.2), cujas informações dos parâmetros encontram-se na tabela 5.1. Os resíduos quantílicos aleatorizados expostos no gráfico normal de probabilidade, exceto pelos poucos pontos afastados da reta, aparentam ser normalmente distribuídos; sugerindo assim, que o modelo foi bem ajustado de forma geral.
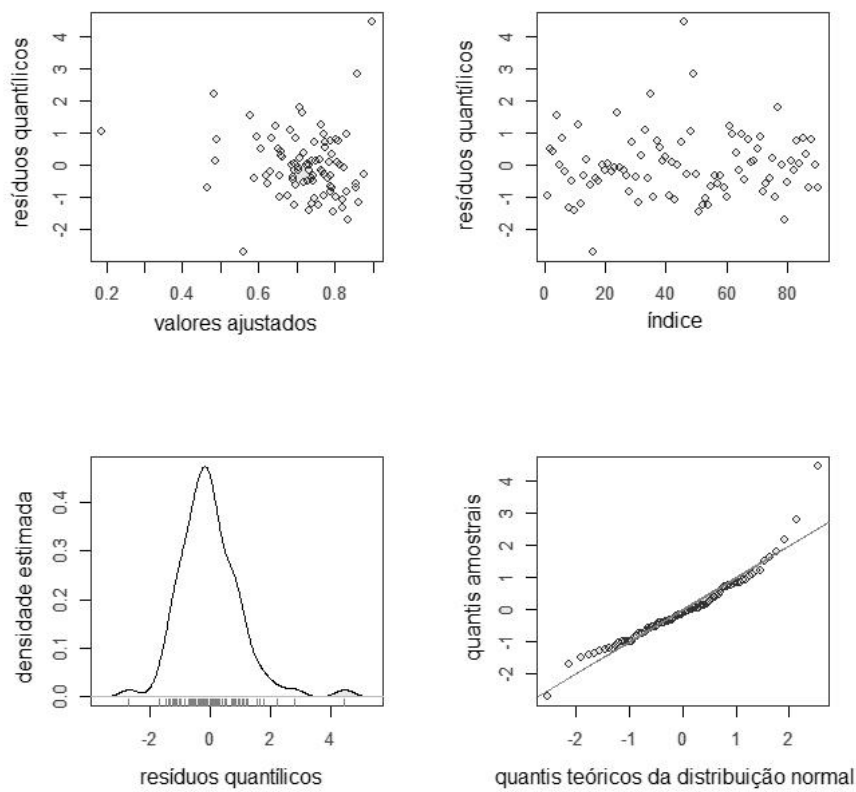

Figura 5.4: Gráficos para diagnóstico do ajuste do modelo para a variável peso ao nascer dos dados de recém-nascidos. 


\begin{tabular}{c|c|c|c|c|c}
\hline Parâmetro & Covariável associada & Estimativa & Erro padrão & Valor t & $p$-valor \\
\hline$\beta_{0}$ & - & $-18,092$ & 2,478 & $-7,301$ & $<0,001$ \\
$\beta_{1}$ & igrn & 0,4771 & 0,062 & 7,709 & $<0,001$ \\
$\beta_{2}$ & aborto & $-0,2154$ & 0,137 & $-1,577$ & 0,1187 \\
$\beta_{3}$ & sexorn & 0,1421 & 0,133 & 1,070 & 0,2879 \\
$\beta_{4}$ & taxapeso & 0,6033 & 0,349 & 1,730 & 0,0873 \\
$\gamma$ & - & 0,1115 & & & \\
\hline
\end{tabular}

Tabela 5.1: Estimativas dos parâmetros, erros padrões, valores $t$ e p-valores do modelo ajustado para a variável peso ao nascer dos dados de recém-nascidos.

As variáveis selecionadas pelo critério AIC permaneceram no modelo, ainda que o teste correspondente tenha apresentado um $p$-valor superior a 0,1 , inclusive por sugestão dos especialistas. A variável sexorn, apesar de apresentar $p$-valor demasiadamente superior a $10 \%$, foi incorporada ao modelo pois os especialistas preferem analisar dados de recém-nascidos de forma separada para meninos e meninas.

Note que as estimativas dos coeficientes das variáveis igrn, sexorn e taxapeso são positivas; isto significa que bebês advindos de gestações mais longas apresentaram, em média, maior peso ao nascer que bebês com menor tempo de gestação, como é esperado. Segundo este modelo, espera-se que bebês do sexo masculino apresentem um peso maior ao nascer que os do sexo feminino. Observase também que a relação entre o ganho de peso das mães por semana gestacional e os pesos dos recém-nascidos é crescente.

\begin{tabular}{c|c|c|c|c|c}
\hline Base de dados & $\widehat{\gamma}$ & Método & $\widehat{\alpha}_{0}$ & $\widehat{\alpha}_{1}$ & $\widehat{\alpha}_{2}$ \\
\hline Base de ajuste & 0,1115 & pacote gamlss & $-0,1215$ & 0,1231 & $-0,0015$ \\
& & MPE & $-0,0275$ & $-0,0254$ & $-0,0303$ \\
\hline \multirow{2}{*}{ Base completa } & \multirow{2}{*}{0,0003} & pacote gamlss & $-1,48 \mathrm{e}-06$ & $2,04 \mathrm{e}-06$ & $-5,67 \mathrm{e}-07$ \\
& & MPE & $-6,87 \mathrm{e}-07$ & $-1,31 \mathrm{e}-06$ & $-7,83 \mathrm{e}-07$ \\
\hline
\end{tabular}

Tabela 5.2: Valores preditos dos interceptos aleatórios do modelo ajustado para a variável peso ao nascer para cada grupo dos dados de recém-nascidos.

A tabela 5.2 apresenta os valores preditos dos efeitos aleatórios do modelo ajustado (5.2) por meio de dois métodos: pelo pacote gamlss do software $\mathrm{R}$ e pelo melhor preditor empírico dado na equação (3.10). Estes valores foram preditos considerando a base de ajuste, que contém informações de apenas 90 gestantes e, considerando a base de dados contendo as informações de todas as 130 gestantes (base completa).

Analisando as informações expostas na tabela 5.2 percebe-se que, ao considerar a base completa, ambos os métodos tiveram resultados semelhantes; no sentido de obter valores preditos próximos de zero. Porém, quando apenas as informações da base de ajuste são consideradas, os métodos apresentam resultados divergentes. Nota-se também que o MPE conseguiu assimilar as diferenças entre os grupos na base completa apenas com as informações da base de ajuste, enquanto o pacote 
gamlss não conseguiu captar toda a informação do estudo ao considerar somente a base de ajuste.

Após modelar os dados, as predições dos termos $\mu_{i j}$ foram obtidas conforme a expressão (3.13). Optou-se por disponibilizar essas informações ao leitor através de gráficos, pela facilidade de visualização e interpretação que eles proporcionam. Dessa forma, no gráfico da figura 5.5 encontram-se os valores observados dos pesos dos recém-nascidos juntamente com os valores preditos pelo MPE.

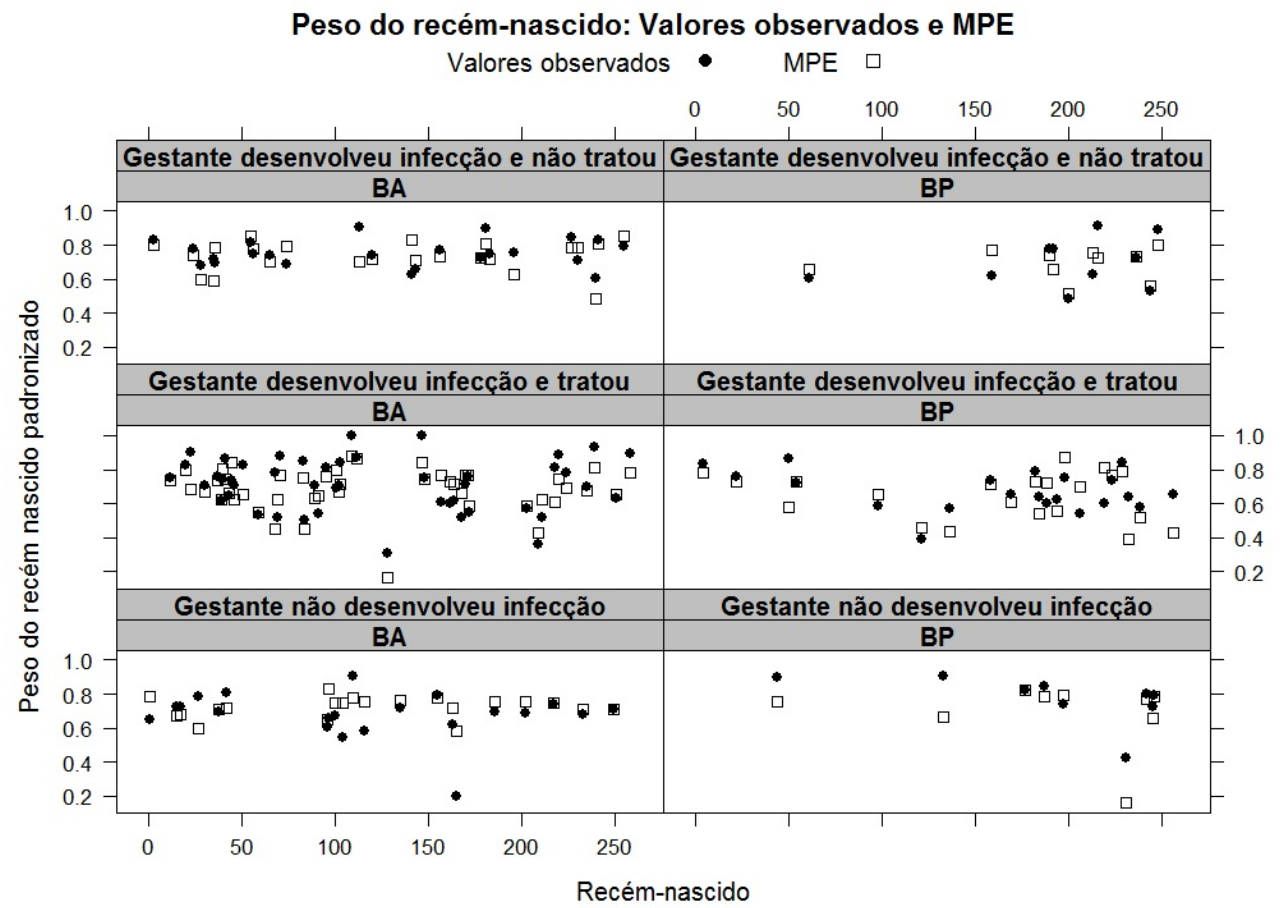

Figura 5.5: Valores observados e MPE da variável peso ao nascer segundo a variável infecção nos dados de recém-nascidos.

Por fim, para melhor ilustrar o uso das predições calculadas, considere que a gestante 177 esteja na última consulta antes do nascimento de seu bebê.

Sabe-se que a gestante engordou $0,305 \mathrm{Kg} /$ semana e que não desenvolveu infecção urinária, nunca abortou, que seu bebê é do sexo masculino e que seu nascimento está previsto para o meio da $40^{a}$ semana gestacional. Utilizando-se do melhor preditor empírico dado na expressão (3.13), o médico obteve que o valor predito de $\mu_{0,177}$ é igual a 0,8260 , que equivale a $3.547,99$ gramas na escala original da variável.

Por meio do pacote gamlss do software $\mathrm{R}$ este mesmo valor foi predito e o resultado foi igual a 0,8128 , cujo valor correspondente na escala original é $3.505,35$ gramas. Como o valor observado foi de 0,8235 (na escala original igual a 3.540 gramas), tem-se que o resultado obtido pelo pacote gamlss foi menos próximo do valor observado que o MPE, porém os valores dos dois métodos foram similares; isto é esperado pois ambos se utilizam das mesmas estimativas dos parâmetros.

\subsection{Dados de pacientes diagnosticados com periodontite}

Periodontite é uma doença inflamatória que ocorre nos tecidos responsáveis pela sustentação do dente (periodonto); ela pode ocasionar mobilidade e até perda dos dentes afetados pela doença. 
Esta é uma moléstia em constante estudo na área de saúde pública, pois ela pode contribuir para o agravamento ou desenvolvimento de outras doenças, inclusive em outras partes do corpo e órgãos. Muitos estudos, como os apresentados em Buhlin et al. (2003) e Cairo et al. (2008), investigam esta contribuição da periodontite em doenças cardiovasculares, isto ocorre pela alta incidência de óbitos na população mundial em função destas doenças.

Segundo a organização mundial da saúde (OMS) mais de 21,88\% dos óbitos ocorridos no mundo em 2011 foram ocasionados por doenças cardiovasculares (World Health Organization et al. (2011)), portanto é de interesse mundial que se conheça os fatores agravantes ou de risco destas moléstias, como o pode ser a periodontite. Com estes conhecimentos disponíveis, os governos possuem a possibilidade de melhor delinear seus projetos para a área da saúde.

Em estudos deste escopo costuma-se considerar como indicadores de risco de problemas cardiovasculares os perfis dos componentes hematológicos e dos lipídios. Um dos indicadores lipídicos é a lipoproteína de baixa densidade oxidada (LDL oxidada), a qual é uma medida de distinção de pacientes com risco de doenças cardiovasculares muito útil na fase de avaliação.

A LDL oxidada é aferida em exames clínicos através da concentração de anticorpos anti-LDL oxidada (anti-oxLDL). Assim sendo, nesta aplicação deseja-se estudar, através de uma amostra de pacientes que passaram pelo tratamento de periodontite, o comportamento de anti-oxLDL e de outros indicadores de doenças cardiovasculares em diferentes momentos do período pós-tratamento.

Veja que, dessa forma, pode-se elucidar a respeito da influência da periodontite no desenvolvimento ou agravamento de doenças cardiovasculares e assim avaliar o sucesso do tratamento em outros aspectos além dos odontológicos. Para tal, a predição destes indicadores se faz útil aos pesquisadores tanto para adquirir conhecimentos, quanto para o auxílio de tomada de decisões no tratamento de novos pacientes.

O banco de dados utilizado nesta segunda aplicação da dissertação é composto por dados de exames clínicos de 40 pacientes que passaram pelo tratamento de periodontite. As informações foram coletadas em quatro momentos distintos: antes do início do tratamento, 3 meses após o tratamento, 6 meses após o tratamento e 12 meses após o tratamento. Dessa forma, na figura 5.6 encontra-se a estrutura hierárquica destes dados. 


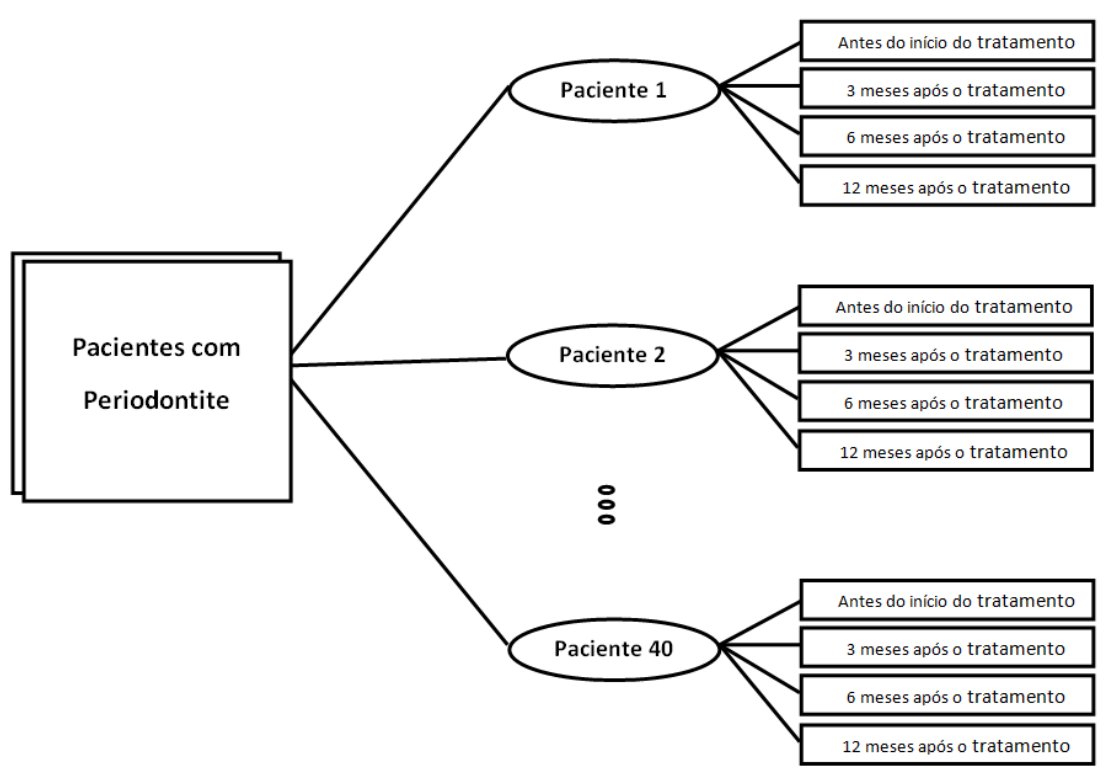

Figura 5.6: Estrutura hierárquica dos dados de periodontite.

Estes dados foram anteriormente analisados em Monteiro et al. (2012) e neste trabalho encontramse detalhes dos meios de seleção dos pacientes e dos procedimentos de coleta de dados.

Em Monteiro et al. (2012) considerou-se a análise destes dados através de modelos mistos normais e, para tal, os autores se valeram de transformações das variáveis resposta nos casos em que as mesmas não eram normalmente distribuídas.

Então, como alternativa a essa forma de análise, optou-se por fazer uso dos modelos beta mistos; assim, não existe necessidade de transformações da variável resposta e a interpretação dos resultados é facilitada por ser feita na mesma escala desta variável.

\subsubsection{Análises}

A variável resposta a ser analisada no presente estudo (anti-oxLDL) segue, por natureza, as mesmas restrições que a variável resposta da aplicação anterior (peso do bebê ao nascer). Logo, para fins de análise exploratória dos dados para verificar a adequabilidade de se ajustar o modelo de regressão beta à variável anti-oxLDL, trabalhou-se com a sua versão padronizada (transformada) segundo a equação (5.1).

A partir deste ponto, ao mencionar a variável anti-oxLDL entenda-se que refere-se a sua versão padronizada.

A seguir encontram-se as variáveis da base de dados que foram selecionadas para a aplicação desenvolvida nesta seção:

1. anti-oxLDL : unidades de anticorpos anti-LDL oxidada;

2. sexo: sexo do paciente;

3. idade : idade do paciente (em anos);

4. raça : raça declarada pelo próprio paciente; 
5. imc : índice de massa corporal do paciente (IMC);

6. $H D L$ : concentração de HDL $(\mathrm{mg} / \mathrm{dL})$;

7. $L D L$ : concentração de LDL $(\mathrm{mg} / \mathrm{dL})$;

8. $P C R$ : concentração de proteína C-reativa $(\mathrm{em} \mathrm{mg} / \mathrm{mL})$;

9. $P B>4 \mathrm{~mm}$ : porcentagem de bolsas periodontais com profundidade superior a $4 \mathrm{~mm}$.

Neste caso optou-se por dividir os dados, aleatoriamente, em duas bases: a base de ajuste (BA) e a base de predição (BP). A primeira é composta por $70 \%$ dos pacientes e a segunda pelos restantes $30 \%$ dos 40 pacientes.

Iniciando a análise exploratória dos dados, a figura 5.7 apresenta o gráfico de perfis da variável anti-oxLDL nas bases de ajuste e de predição.
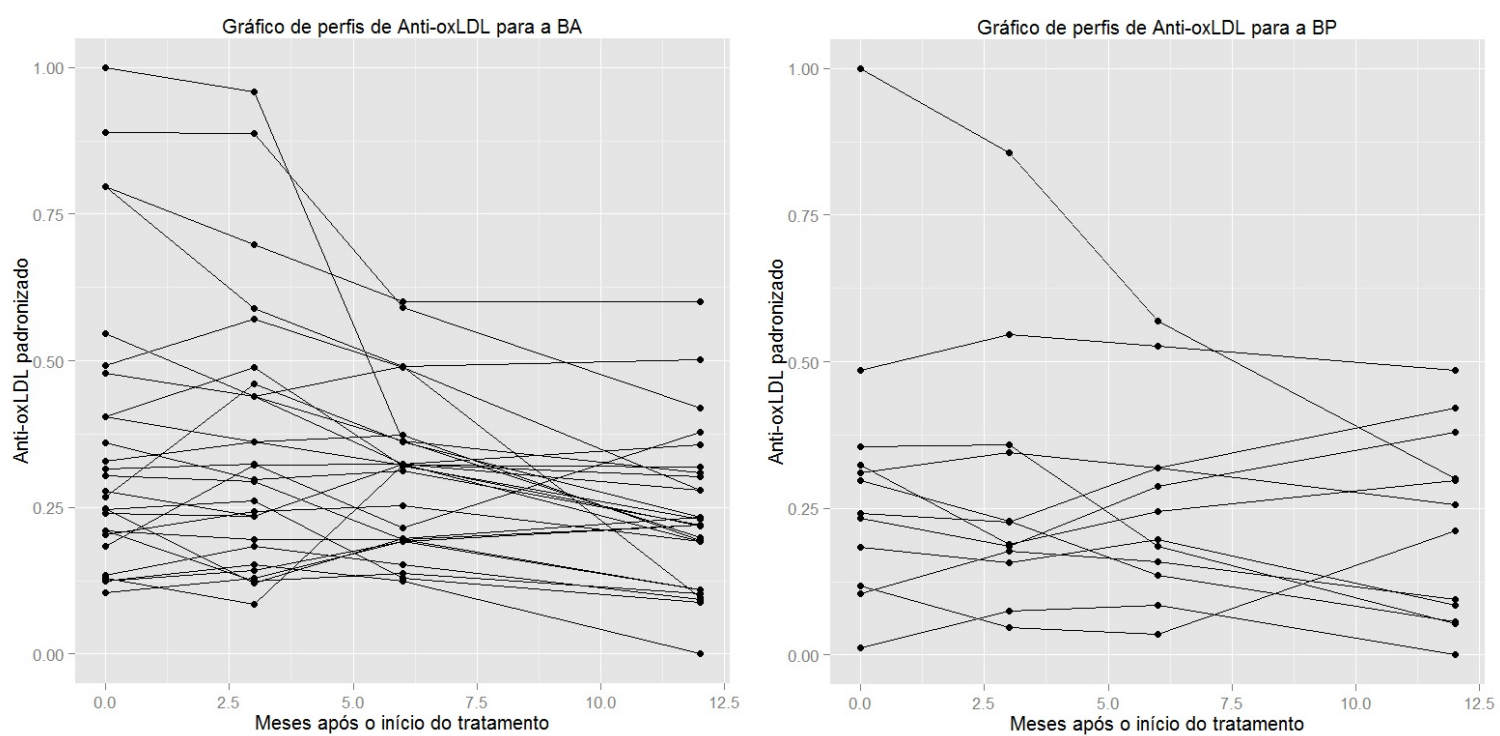

Figura 5.7: Gráfico de perfis da variável anti-oxLDL para as bases de ajuste e de predição nos dados de periodontite.

$\mathrm{Na}$ base de predição um paciente apresenta valor de anti-oxLDL aparentemente atípico antes de passar pelo tratamento de periodontite (se comparado com a mesma medida em outros pacientes), porém na base de ajuste não observa-se nenhum paciente com tal comportamento.

Note, na figura 5.7, que o comportamento decrescente de anti-oxLDL a medida que o tempo decorrente do início do tratamento aumenta é predominante, indicando o sucesso do tratamento com relação a esta variável. Porém, a intensidade deste decrescimento varia muito entre os pacientes, sugerindo fortemente a utilização de efeitos aleatórios no modelo.

Dado que a análise anterior sugeriu a utilização dos modelos com efeitos aleatórios, convém continuar a análise estudando o histograma da variável resposta para definir qual é a distribuição de probabilidades mais apropriada para representá-la. 


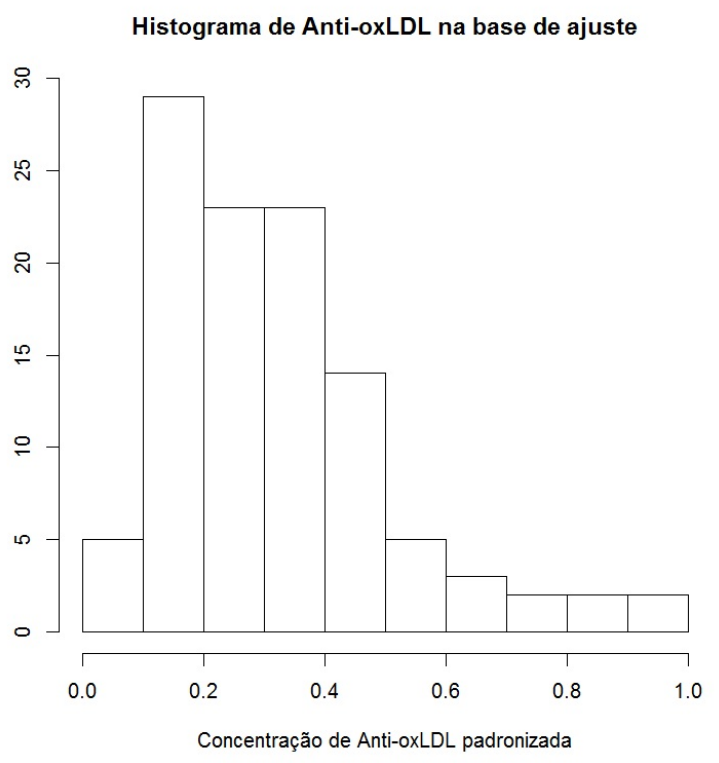

Figura 5.8: Histograma da variável anti-oxLDL da base de ajuste.

A figura 5.8 expõe o histograma da variável anti-oxLDL para a base de ajuste; nele, verifica-se que os dados se concentram no intervalo $(0,1 ; 0,2)$, mas continuam tendo grande incidência nos intervalos $(0,2 ; 0,3)$ e $(0,3 ; 0,4)$. Este comportamento assimétrico, juntamente com a característica de continuidade no intervalo $(0,1)$, indica a adequabilidade de se considerar a distribuição de probabilidade beta para a variável em questão.

Seguindo os roteiros sugeridos para análises de dados longitudinais por Cnaan et al. (1997), McCulloch et al. (2008), Lin e Lee (2008) e Diggle et al. (2013), prosseguiu-se a aplicação com o ajuste do modelo de regressão que a análise exploratória dos dados indicou como sendo adequado.

O modelo inicialmente ajustado para a variável anti-oxLDL possui como variáveis explicativas as variáveis $2,3, \ldots$ e 9 , anteriormente apresentadas. Elas foram previamente selecionadas pelos profissionais da saúde por possuírem potencial de influenciar nos valores de LDL oxidada.

Após o ajuste desse modelo inicial, foi aplicado o método de seleção de variáveis AIC e, juntamente com os conhecimentos práticos do assunto estudado, conclui-se que um modelo útil, coerente e parcimonioso é o apresentado na equação (5.3).

$\log \left(\frac{\mu_{i j}}{1-\mu_{i j}}\right)=\beta_{0}+\beta_{1} m e s .3_{i j}+\beta_{2} m e s .6_{i j}+\beta_{3} m e s .12_{i j}+\beta_{4} H D L_{i j}+\beta_{5} L D L_{i j}+\alpha_{i}$

onde:

- $i$ indica o paciente em questão;

- $j$ indica o número de meses decorridos pós-tratamento:

- $j=0$ indica que as aferições ocorreram antes do início do tratamento;

- $j=3$ indica que as aferições ocorreram 3 meses após o início do tratamento;

- $j=6$ indica que as aferições ocorreram 6 meses após o início do tratamento; 
- $j=12$ indica que as aferições ocorreram 12 meses após o início do tratamento.

- $y_{i j}$ é o número de anticorpos contra LDL oxidada do $i$-ésimo paciente no $j$-ésimo mês póstratamento;

- mes. $3_{i j}$ é a variável indicadora que assume valor 1 se $j=3$ e assume valor 0 caso contrário.

Da mesma forma foram construídas as variáveis mes. $6_{i j}$ e mes. $12_{i j}$;

- $\alpha_{i}$ é o intercepto aleatório associado ao $i$-ésimo paciente;

- $\alpha_{1}, \alpha_{2}, \ldots, \alpha_{40}$ são independentes e identicamente distribuídos $N\left(0, \gamma^{2}\right)$;

- $Y_{i j} \mid \alpha_{i}$ são condicionalmente independentes e possuem distribuição $\operatorname{Beta}\left(\mu_{i j}, \phi\right)$ e;

- $\beta_{0}, \beta_{1}, \beta_{2}, \beta_{3}, \beta_{4}, \beta_{5}, \gamma$ e $\phi$ são parâmetros do modelo.

Os gráficos de diagnóstico do modelo escolhido encontra-se na figura 5.9, e sugerem a bondade do ajuste, apesar da presença de um ponto mais afastado da reta no canto superior direito do gráfico QQ-plot.
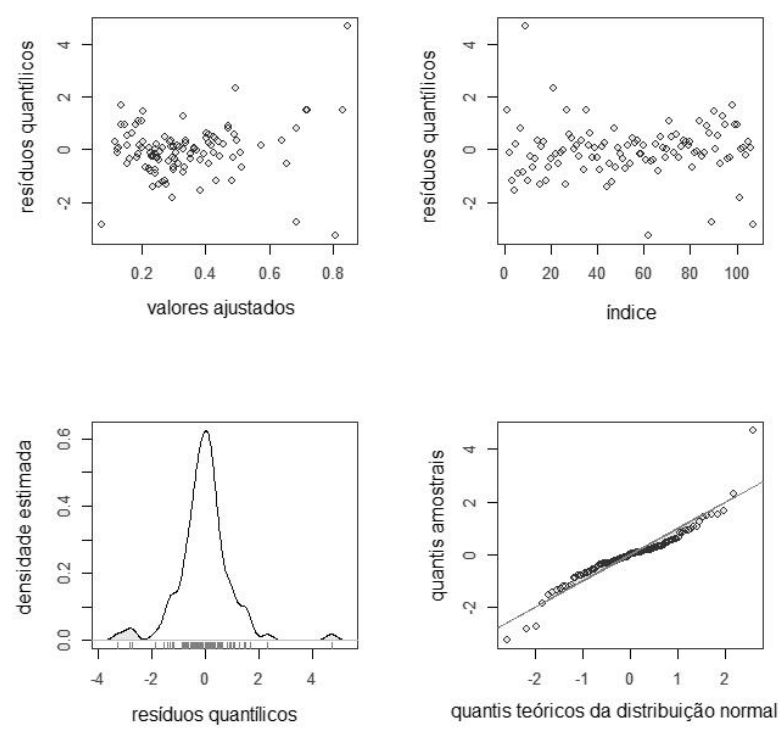

Figura 5.9: Gráficos para diagnóstico do ajuste do modelo para a variável anti-oxLDL dos dados de periodontite.

Enfim, a tabela 5.3 apresenta as informações relacionadas aos parâmetros do modelo (5.3). 


\begin{tabular}{c|c|c|c|c|c}
\hline Parâmetro & Covariável associada & Estimativa & Erro padrão & Valor t & $p$-valor \\
\hline$\beta_{0}$ & - & $-1,989$ & 0,407 & $-4,885$ & $<0,001$ \\
$\beta_{1}$ & mes.3 & $-0,129$ & 0,160 & $-0,806$ & 0,423 \\
$\beta_{2}$ & mes.6 & $-0,359$ & 0,162 & $-2,219$ & 0,029 \\
$\beta_{3}$ & mes.12 & $-0,873$ & 0,168 & $-5,184$ & $<0,001$ \\
$\beta_{4}$ & HDL & 0,0138 & 0,008 & 1,797 & 0,076 \\
$\beta_{5}$ & LDL & 0,0075 & 0,002 & 4,098 & $<0,001$ \\
$\gamma$ & - & 0,5359 & & & \\
\hline
\end{tabular}

Tabela 5.3: Estimativas dos parâmetros, erros padrões, valores $t$ e p-valores do modelo ajustado para a variável anti-oxL $\boldsymbol{D L}$ dos dados de periodontite.

Veja, na tabela 5.3, que os coeficientes relacionados às variáveis indicadoras de tempo póstratamento são negativos, isto significa que o valor de anti-oxLDL antes do início do tratamento é, em média, maior do que o mesmo após o início do tratamento.

Os valores absolutos destes coeficientes são maiores conforme o número de meses pós-tratamento aumenta; ou seja, ao comparar os valores de anti-oxLDL pré-tratamento com os mesmos após o início do tratamento, em média, a intensidade da diminuição deste indicador é maior conforme o número de meses procedentes ao tratamento aumenta.

A covariável LDL apresentou coeficiente associado positivo, sugerindo que a LDL oxidada média aumenta conforme o valor desta variável se eleva, assim como é esperado segundo os especialistas.

Retomando os objetivos da pesquisa, ao considerar a variável anti-oxLDL como indicadora de risco de doenças cardiovasculares, os resultados obtidos até o presente momento mostram que o fator de risco de doenças cardiovasculares em pacientes com periodontite diminui conforme o tempo pós-tratamento aumenta.

Isto significa também que o tratamento recebido pelos pacientes permanece surtindo efeito e sendo eficaz neste primeiro ano que o sucede.

Dando prosseguimento ao estudo dos dados, foram calculadas as predições do termo $\mu_{i j}$ conforme a expressão (3.13). Estes valores encontram-se na figura 5.10 para os pacientes que compõem a base de ajuste e na figura 5.11 para os pacientes provenientes da base de predição. 


\section{Anti-oxLDL: valores observados e MPE para a BA Valores observados MPE 口}

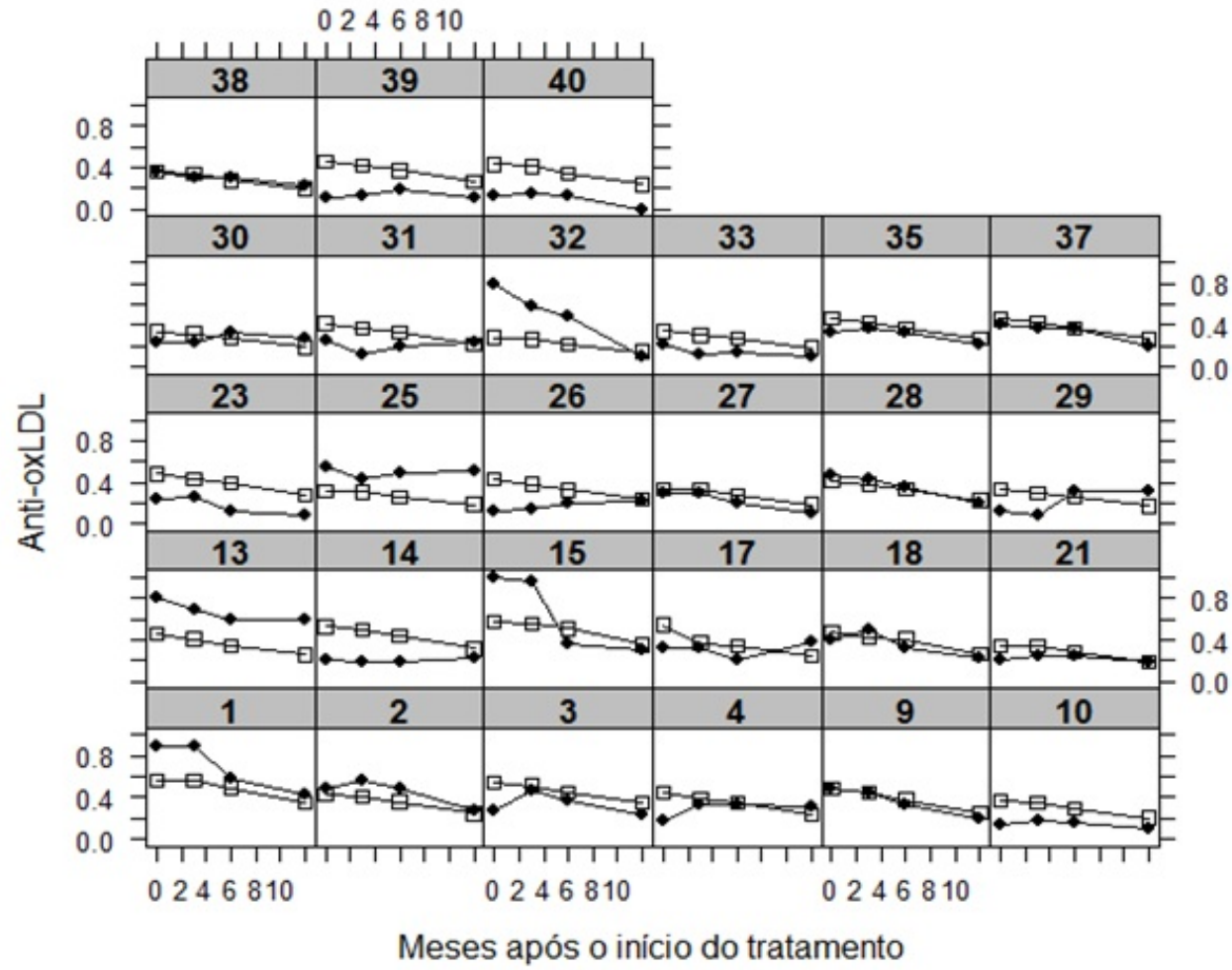

Figura 5.10: Valores observados e MPE da variável anti-oxLDL para os pacientes da BA nos dados de periodontite.

\section{Anti-oxLDL: valores observados e MPE para a BP}

Valores observados

MPE 口

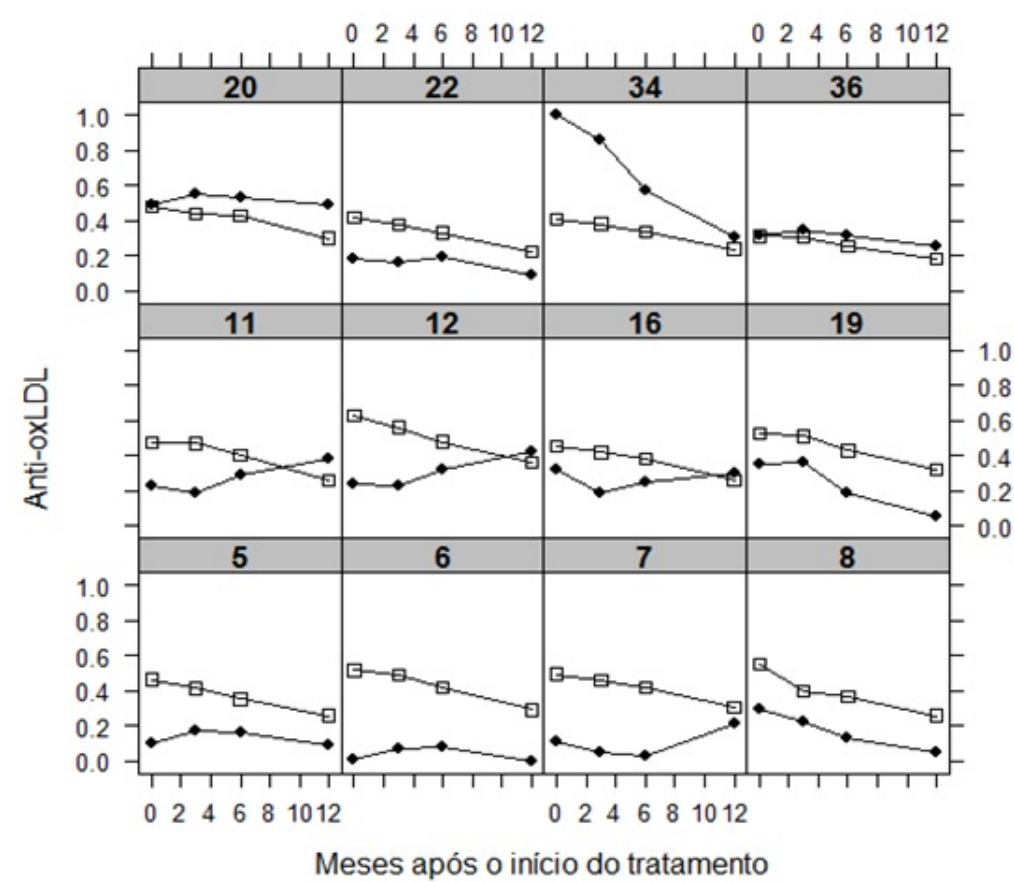

Figura 5.11: Valores observados e MPE da variável anti-oxLDL para os pacientes da BP nos dados de periodontite. 
Ressalta-se novamente que em situações práticas não se conhece o verdadeiro valor do termo $\mu_{i j}$, como acontece nos estudos de simulação. Com isso, não é apropriado analisar o desempenho preditivo do MPE nesta aplicação através das diferenças entre os valores observados e preditos. A forma mais eficiente de analisar este desempenho é observar a fidelidade com que o método preditivo assimila as tendências de crescimento e decrescimento dos valores de anti-oxLDL aferidos em cada paciente nos diversos momentos.

A observação das informações de cada paciente nos resultados expostos na figura 5.10 indica que diversos tipos de desempenhos foram obtidos:

- em alguns pacientes, como $9,10,27,28,35,37$ e 40, a tendência dos valores observados foi perfeitamente assimilada pelo preditor;

- em outros casos, por exemplo os pacientes 15 e 32, a tendência de crescimento e/ou decrescimento foi captada pelo MPE, porém, a intensidade que este fenômeno ocorre entre alguns períodos de coleta de dados não é devidamente representada nas predições.

Contudo, o desempenho permanece satisfatório e útil aos objetivos desejados;

- em contrapartida, os pacientes 26 e 39 tiveram o comportamento de seus números de anticorpos contra oxLDL entre os meses na coleta erroneamente captados pelo MPE; porém, este fato é esperado em ferramentas como esta e o importante nesta situação é realizar uma análise de diagnóstico mais aprofundada no modelo original.

No caso das predições contabilizadas para a variável anti-oxLDL dos pacientes da base de ajuste, o fato narrado no parágrafo anterior foi esporádico.

Portanto, tendo como base as análises efetuadas, sugere-se que o melhor preditor empírico teve performance eficiente em sua aplicação aos dados da base de ajuste.

Quando se explora os resultados da figura 5.11, observa-se desempenhos muito semelhantes aos obtidos para a base de ajuste. Esta característica referente à semelhança da performance do método em suas aplicações para grupos já estudados e para novos grupos é muito interessante e desejada pelos pesquisadores.

Com isso, assim como obtido nos estudos de simulação, para esta aplicação foi observada a característica de semelhança no desempenho preditivo do MPE nas bases de ajuste e de predição; este aspecto é um quesito promissor desta metodologia apresentada.

Adicionalmente, como forma mais simplista de visualização e de interpretação dos resultados das figuras 5.10 e 5.11, apresenta-se na figura 5.12 o gráfico de perfis médios dos valores observados e preditos da variável anti-oxLDL. 


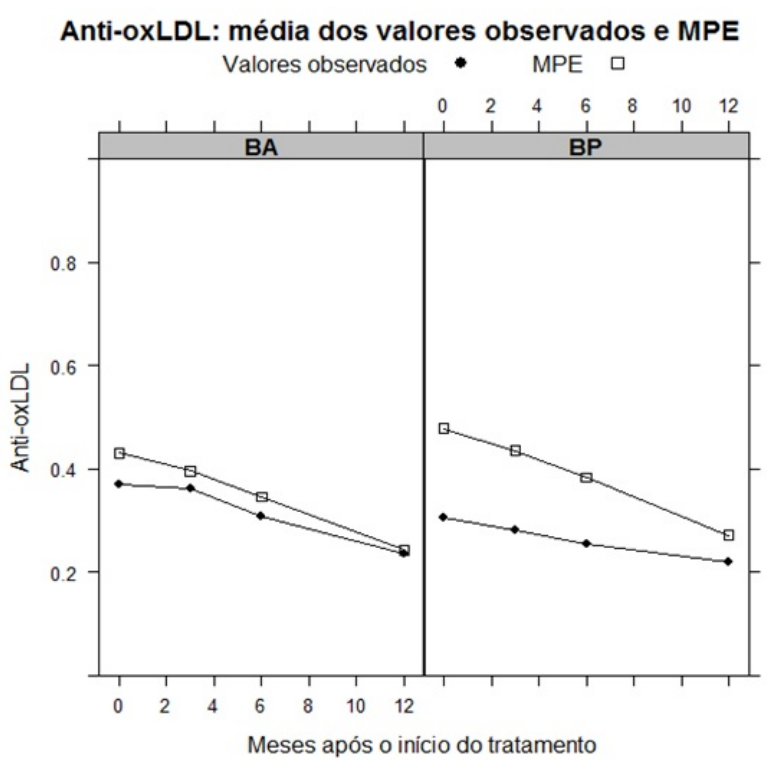

Figura 5.12: Perfis médios dos valores observados e MPE da variável anti-oxLDL dos pacientes nos dados de periodontite.

Os resultados expostos na figura 5.12 mostram que, para as bases de ajuste e de predição desta aplicação, os valores preditos médios de anticorpos anti LDL oxidada apresentam as mesmas tendências observadas nos valores reais aferidos.

No gráfico referente à $\mathrm{BA}$, a intensidade de diminuição de anti-oxLDL entre o $3^{\circ}$ e $6^{\circ}$ mês póstratamento e entre o $6^{\circ}$ e $12^{\circ}$ mês pós-tratamento é muito bem assimilada pelo método preditivo. $\mathrm{O}$ mesmo ocorre no segundo gráfico, referente à $\mathrm{BP}$, para a tendência observada dentre os meses 3 e 6 e entre o início e o $3^{\circ}$ mês procedente ao tratamento.

Portanto, os resultados comentados nos dois parágrafos anteriores confirmam as conclusões dos estudos de simulacão a respeito da eficiência do melhor preditor empírico.

Neste capítulo foi exemplificada a aplicação do MPE nas duas situações possíveis em estudo através da análise de dados de saúde. Os resultados foram satisfatórios e similares aos observados nos estudos de simulação, tanto para o MPE dos efeitos aleatórios, quanto para o MPE da média. 


\section{Capítulo 6}

\section{Conclusão}

Este capítulo tem como intuito revisar o conteúdo apresentado nesta dissertação, fornecendo ao leitor um panorama dos itens estudados e desenvolvidos nela.

Após a leitura destas considerações, fica clara a existência de possibilidades de estudos de outros aspectos e características do MPE desenvolvido no capítulo 3; além da possibilidade de desenvolvê-lo para outras classes de modelos.

\subsection{Considerações Finais}

O crescimento de pesquisas envolvendo dados correlacionados gera a demanda de se estudar técnicas estatísticas adequadas para a análise de dados que apresentam esta estrutura. Intensamente utilizados para esta finalidade, os modelos mistos são apropriados e eficientes quando a distribuição adotada para a variável resposta é corretamente especificada.

Em virtude da flexibilidade da distribuição beta e da possibilidade de seu uso em várias áreas de aplicação, o objetivo desta dissertação é propor um método de predição para os modelos beta com intercepto aleatório normalmente distribuído.

Ao desejar que este método pudesse ser aplicado para novos grupos com a mesma eficiência obtida em sua aplicação para grupos previamente analisados, optou-se por desenvolver o melhor preditor empírico para a classe de modelos beta mistos em estudo.

Denominado melhor preditor empírico (MPE), o método foi desenvolvido para: o caso geral de se ter interesse em predizer qualquer função do componente aleatório do modelo $\left(\zeta\left(\boldsymbol{\beta}, \alpha_{i}\right)\right)$, e também foram detalhadas as expressões para os casos específicos de predição do intercepto aleatório $\left(\alpha_{i}\right)$ e da esperança condicional da variável resposta ao componente aleatório $\left(\mu_{i j}=E\left(Y_{i j} \mid \alpha_{i}\right)\right)$.

Ao apresentar este novo recurso de predição, existe a necessidade de estudar o seu desempenho através de estudos de simulação. Os resultados destes estudos, apresentados no capítulo 4, indicam que a utilização do MPE teve desempenhos muito semelhantes nas predições de grupos já analisados (base de ajuste) e de novos grupos (base de predição) nos aspectos em estudo, sendo de maneira geral satisfatórios. 
Para ilustrar o uso do MPE, foram analisados dois bancos de dados de estudos na área de saúde. Na primeira aplicação o objetivo dos pesquisadores era selecionar quais características clínicas e socioeconômicas de gestantes influenciam no peso de seus bebês ao nascer.

Dentre os resultados obtidos pode-se destacar que o melhor preditor empírico conseguiu captar as diferenças entre os grupos nos dados do estudo usando apenas $70 \%$ das informações que integram a base de ajuste; fato este que não ocorreu com as predições do pacote gamlss. Comparações mais aprofundadas entre ambas as metodologias estão previstas como trabalho futuro.

Em seguida, exemplificando outra faceta de aplicação do MPE, foram analisados dados longitudinais de pacientes diagnosticados com periodontite.

Os esforços empregados no desenvolvimento do melhor preditor empírico, na avaliação de seu desempenho e na ilustração de suas aplicações revelaram resultados promissores.

Após obter estes resultados, os próximos interesses são observar o uso do MPE em outras aplicações, inclusive de áreas diferentes, e expandí-lo de forma a possibilitar seu uso em um maior campo de aplicação. Mais esclarecimentos sobre os possíveis tópicos de estudos futuros encontram-se na seção que segue.

\subsection{Sugestões para Pesquisas Futuras}

A continuidade deste trabalho pode ser feita em diversas vertentes; dentre elas, as principais sugestões de pesquisas futuras que enriqueceriam o conteúdo apresentado são:

- estender o método de predição do melhor preditor empírico para as classes de modelos de regressão beta com um número maior de efeitos aleatórios com distribuição normal e não normal;

- estender o método de predição do melhor preditor empírico para dados hierárquicos com mais de dois níveis;

- estudar a influência da especificação incorreta da distribuição do efeito aleatório nas predições;

- estudar a variabilidade do melhor preditor empírico;

- desenvolver um método de predição que considere a distribuição preditiva para ser aplicado aos modelos beta mistos;

- desenvolver o melhor preditor empírico para a mediana da distribuição beta, com o objetivo de estudar o comportamento da variável resposta dos modelos beta mistos por meio deste preditor; e, comparar seu desempenho para esta finalidade com o do MPE da média;

- avaliar o desempenho do MPE em ajustes com funções de ligação diferentes da logito e;

- comparar o desempenho do MPE com o desempenho de outros métodos de predição. 
Assim, por tudo o que foi exposto, inclusive pelos desafios de pesquisa, acreditamos que a proposta oferece boas perspectivas para o futuro. 
CONCLUSÃO 


\section{Referências Bibliográficas}

Bartlett (1937) M.S. Bartlett. Properties of sufficiency and statistical tests. Proceedings of the Royal Society of London. Series A-Mathematical and Physical Sciences, 160(901):268-282. Citado na pág. 24

Bayes et al. (2012) C.L. Bayes, J.L. Bazán e C. García. A new robust regression model for proportions. Bayesian Analysis, 7(4):841-866. Citado na pág. 7

Buhlin et al. (2003) K. Buhlin, A. Gustafsson, A.G. Pockley, J. Frostegard e B. Klinge. Risk factors for cardiovascular disease in patients with periodontitis. European Heart Journal, 24(23): 2099-2107. Citado na pág. 45

Bussab e Morettin (2013) W.O. Bussab e P.A. Morettin. Estatística básica. Citado na pág. 24

Cairo et al. (2008) F. Cairo, S. Castellani, A.M. Gori, M. Nieri, G. Baldelli, R. Abbate e G.P. Pini-Prato. Severe periodontitis in young adults is associated with sub-clinical atherosclerosis. Journal of clinical periodontology, 35(6):465-472. Citado na pág. 45

Carlin e Louis (2000) B.P. Carlin e T.A. Louis. Empirical Bayes: Past, present and future. Journal of the American Statistical Association, 95(452):1286-1289. Citado na pág. 3, 11

Casella (1985) G. Casella. An introduction to empirical Bayes data analysis. The American Statistician, 39(2):83-87. Citado na pág. 3, 11

Cnaan et al. (1997) A. Cnaan, N.M. Laird e P. Slasor. Tutorial in biostatistics: using the general linear mixed model to analyse unbalanced repeated measures and longitudinal data. Statistics in Medicine, 16:2349-2380. Citado na pág. 48

Cribari-Neto e Souza (2012) F. Cribari-Neto e T.C. Souza. Testing inference in variable dispersion beta regressions. Journal of Statistical Computation and Simulation, 82(12):1827-1843. Citado na pág. 5

Cribari-Neto e Zeileis (2010) F. Cribari-Neto e A. Zeileis. Beta regression in R. Journal of Statistical Software, 34(2):1-24. Citado na pág. 19

Diggle et al. (2013) P. Diggle, P. Heagerty, K.-Y. Liang e S. Zeger. Analysis of longitudinal data. Number 25. Oxford University Press. Citado na pág. 48

Drehmer (2010) M. Drehmer. Ganho de peso gestacional, desfechos adversos da gravidez e retenção de peso pós-parto. Tese de Doutorado, Faculdade de Medicina, Universidade Federal do Rio Grande do Sul, Brasil. Citado na pág. 37

Dunn e Smyth (1996) P.K. Dunn e G.K. Smyth. Randomized quantile residuals. Journal of Computational and Graphical Statistics, 5(3):236-244. Citado na pág. 13

Efron e Morris (1973) B. Efron e C. Morris. Stein's estimation rule and its competitors - an empirical Bayes approach. Journal of the American Statistical Association, 68(341):117-130. Citado na pág. 11 
Farrell et al. (1997) P.J. Farrell, B. MacGibbon e T.J. Tomberlin. Empirical Bayes estimators of small area proportions in multistage designs. Statistica Sinica, 7(4):1065-1083. Citado na pág. 11

Ferrari e Cribari-Neto (2004) S. Ferrari e F. Cribari-Neto. Beta regression for modelling rates and proportions. Journal of Applied Statistics, 31(7):799-815. Citado na pág. 5, 7

Figueroa-Zúñiga et al. (2013) J.I. Figueroa-Zúñiga, R.B. Arellano-Valle e S.L.P. Ferrari. Mixed beta regression: A bayesian perspective. Computational Statistics \&f Data Analysis, 61(0):137147. Citado na pág. 2,9

Fitzmaurice et al. (2008) G. Fitzmaurice, M. Davidian, G. Verbeke e G. Molenberghs. Longitudinal data analysis. CRC Press. Citado na pág. 2, 11

Fu e Wang (2012) L. Fu e Y.-G. Wang. Quantile regression for longitudinal data with a working correlation model. Computational Statistics and Data Analysis, 56(8):2526-2538. Citado na pág. 25

Grün et al. (2012) B. Grün, I. Kosmidis e A. Zeileis. Extended beta regression in R: Shaken, stirred, mixed, and partitioned. Journal of Statistical Software, 48(11):1-25. Citado na pág. 19

Guoyou e Zhongyi (2008) Q. Guoyou e Z. Zhongyi. Robust estimation in partial linear mixed model for longitudinal data. Acta Mathematica Scientia, 28(2):333-347. Citado na pág. 25

Hernández (2013) F. Hernández. Modelos multiniveis Weibull com efeitos aleatórios. Tese de Doutorado, Instituto de Matemática e Estatística, Universidade de São Paulo, Brasil. Citado na pág. 8

Hernández et al. (2013) F. Hernández, O. Usuga e V. Giampaoli. Improving the adaptive gaussian quadrature. não publicado. Citado na pág. 9, 19

Jiang e Lahiri (2001) J. Jiang e P. Lahiri. Empirical best prediction for small area estimation with binary data. Annals of the Institute of Statistical Mathematics, 53(2):217-243. Citado na pág. 11

Jiang e Lahiri (2006) J. Jiang e P. Lahiri. Mixed model prediction and small area estimation. Test, 15(1):1-96. Citado na pág. 11, 16

Kieschnick e McCullough (2003) R. Kieschnick e B.D. McCullough. Regression analysis of variates observed on $(0,1)$ : percentages, proportions and fractions. Statistical Modelling, 3(3): 193-213. Citado na pág. 7

Laird e Ware (1982) N.M. Laird e J.H. Ware. Random-effects models for longitudinal data. Biometrics, 38(4):963-974. Citado na pág. 1

Lin e Lee (2008) T.I. Lin e J.C. Lee. Estimation and prediction in linear mixed models with skew-normal random effects for longitudinal data. Statistics in medicine, 27(9):1490-1507. Citado na pág. 48

Liu e Pierce (1994) Q. Liu e D.A. Pierce. A note on Gauss-Hermite quadrature. Biometrika, 81 (3):624-629. Citado na pág. 9, 19

Magalhães e Lima (2000) M.N. Magalhães e A.C.P. Lima. Noções de probabilidade e estatística. IME-USP. Citado na pág. 24

McCulloch e Neuhaus (2011) C.E. McCulloch e J.M. Neuhaus. Prediction of random effects in linear and generalized linear models under model misspecification. Biometrics, 67(1):270-279. Citado na pág. 12

McCulloch et al. (2008) C.E. McCulloch, S.R. Searle e J.M. Neuhaus. Generalized, Linear, and Mixed Models. Wiley. Second Edition. Citado na pág. 2, 10, 11, 48 
McDermott et al. (2000) S. McDermott, W. Callaghan, L. Szwejbka, H. Mann e V. Daguise. Urinary tract infections during pregnancy and mental retardation and developmental delay. Obstetrics $\mathscr{E}$ Gynecology, 96(1):113-119. Citado na pág. 37, 40

Monteiro et al. (2012) A.M. Monteiro, M.A.N. Jardini, V. Giampaoli, S.Alves, A.M.F. Neto e M. Gidlund. Measurement of the nonlinear optical response of low-density lipoprotein solutions from patients with periodontitis before and after periodontal treatment: evaluation of cardiovascular risk markers. Journal of biomedical optics, 17(11):115004. Citado na pág. 46

Morris (1983) C. Morris. Parametric empirical Bayes inference: theory and applications. Journal of the American Statistical Association, 78(381):47-55. Citado na pág. 3, 11

Paolino (2001) P. Paolino. Maximum likelihood estimation of models with beta-distributed dependent variables. Political Analysis, 9(4):325-346. Citado na pág. 7

Papoila (2012) A.L. Papoila. Modelos de predição em medicina: Algumas considerações. Métodos Estatísticos em Medicina, páginas 26-35. Citado na pág. 37

Park e Wu (2006) J.-G. Park e H. Wu. Backfitting and local likelihood methods for nonparametric mixed-effects models with longitudinal data. Journal of statistical planning and inference, 136 (11):3760-3782. Citado na pág. 25

R Developement Core Team and others (2013) R Developement Core Team and others. R: A language and environment for statistical computing, 2013. R Foundation for Statistical Computing. Vienna, Austria, 2013. url: http://www. R-project. org. Citado na pág. 10

Rigby e Stasinopoulos (2005) R.A. Rigby e D.M. Stasinopoulos. Generalized additive models for location, scale and shape. Applied Statistical, 54(3):507-554. Citado na pág. 2, 7, 13

Ross (2009) S.M. Ross. Introduction to probability and statistics for engineers and scientists. Citado na pág. 24

Shapiro e Wilk (1965) S.S. Shapiro e M.B. Wilk. An analysis of variance test for normality (complete samples). Biometrika, 52(3/4):591-611. Citado na pág. 24

Sheiner e Beal (1981) L.B. Sheiner e S.L. Beal. Some suggestions for measuring predictive performance. Journal of Pharmacokinetics and Biopharmaceutics, 9(4):503-512. Citado na pág. 12

Silva e Giampaoli (2013) T.C.M. Silva e V. Giampaoli. Relatório de análise estatística sobre o projeto: Alterações da composição corporal durante a gestação e sua associação com o peso ao nascer. Instituto de Matemática e Estatística, Universidade de São Paulo, Brasil (RAE-CEA13P15). Citado na pág. 38

Simas et al. (2010) A.B. Simas, W. Barreto-Souza e A.V. Rocha. Improved estimators for a general class of beta regression models. Computational Statistics 83 Data Analysis, 54(2):348-366. Citado na pág. 7

Snedecor e Cochran (1989) G.W. Snedecor e W.G. Cochran. Statistical methods 8th edition. Citado na pág. 24

Stasinopoulos et al. (2008) M. Stasinopoulos, B. Rigby e C. Akantziliotou. Instructions on how to use the gamlss package in R, January 2008. Second Edition. Citado na pág. 10

Steyeberg et al. (2010) E.W. Steyeberg, A.J. Vickers, N.R. Cook, T. Gerds, M. Gonem, N. Obuchowski, M.J. Pencina e M.W. Kattan. Assessing the performance of prediction models: a framework for traditional and novel measures. Epidemiology, 21(1):128-138. Citado na pág. 11 
Tamura (2007) K.A. Tamura. Modelo logístico multinível: Um enfoque em métodos de estimação e predição. Dissertação de Mestrado, Instituto de Matemática e Estatística, Universidade de São Paulo, Brasil. Citado na pág. 9, 11

Tamura (2012) K.A. Tamura. Métodos de predição para o modelo logístico misto com $k$ efeitos aleatórios. Tese de Doutorado, Instituto de Matemática e Estatística, Universidade de São Paulo, Brasil. Citado na pág. 3, 11, 16

Tamura e Giampaoli (2013) K.A. Tamura e V. Giampaoli. New prediction method for the mixed logistic model applied in a marketing problem. Computational Statistics \& Data Analysis, 66(0):202 - 216. Citado na pág. 11

Tamura e Giampaoli (2010) K.A. Tamura e V. Giampaoli. Prediction in multilevel logistic regression. Communications in Statistics-Simulation and Computation, 39(6):1083-1096. Citado na pág. 11

Usuga (2013) O.C. Usuga. Modelos de regressão beta com efeitos aleatórios normais e não normais para dados longitudinais. Tese de Doutorado, Instituto de Matemática e Estatística, Universidade de São Paulo, Brasil. Citado na pág. 2, 3, 7, 9, 10, 11

Verbeke e Molenberghs (2009) G. Verbeke e G. Molenberghs. Linear mixed models for longitudinal data. Springer. Citado na pág. 2, 11

Verkuilen e Smithson (2012) J. Verkuilen e M. Smithson. Mixed and mixture regression models for continuous bounded responses using the beta distribution. Journal of Educational and Behavioral Statistics, 37(1):82-113. Citado na pág. 2, 9

World Health Organization et al. (2011) WHO World Health Organization, World Heart Federation e World Stroke Organization. Global atlas on cardiovascular disease prevention and control. Citado na pág. 45 